Signal Strength, Media Attention, and Resource Mobilization: Evidence from New Private Equity Firms

\begin{tabular}{|c|l|}
\hline Journal: & Academy of Management Journal \\
\hline Manuscript ID & AMJ-2018-0356.R2 \\
\hline Manuscript Type: & Revision \\
\hline Keywords: & $\begin{array}{l}\text { Financing of new ventures (IPOs, venture capital, etc.) } \\
\text { Entrepreneurship < Topic Areas, New venture strategies < } \\
\text { Entrepreneurship < Topic Areas, Entrepreneurship (General) } \\
\text { Entrepreneurship < Topic Areas, Organization and management theory } \\
\text { (General) < Organization and Management Theory < Topic Areas }\end{array}$ \\
\hline \multirow{5}{*}{ Abstract: } & $\begin{array}{l}\text { Past research has shown that new firms can facilitate resource } \\
\text { mobilization by signaling their unobservable quality to prospective } \\
\text { resource providers. However, we know less about situations in which } \\
\text { firms convey multiple signals of different strengths-i.e., signals that are } \\
\text { more or less correlated with unobservable firm quality. Building on a } \\
\text { sociocognitive perspective, we propose that prospective resource } \\
\text { providers respond differently to signals of different strengths and that } \\
\text { the effectiveness of signals, especially weak signals, will be contingent } \\
\text { on the media attention new firms receive. Empirically, we conduct a } \\
\text { longitudinal analysis examining the ability of new private equity (PE) } \\
\text { firms to raise a follow-on fund. Consistent with our theory, we find that } \\
\text { unrealized performance, a relatively weak signal, positively influences } \\
\text { fundraising. But we fail to find statistical evidence that its effect is } \\
\text { weaker than that of realized performance, a relatively strong signal. } \\
\text { Further, media attention strengthens the relationship between unrealized } \\
\text { performance and fundraising, but media attention exerts less impact on } \\
\text { the relationship between realized performance and fundraising. Taken } \\
\text { together, our findings deepen our understanding of how new firms can } \\
\text { mobilize resources with signals of different strengths and of how the } \\
\text { media-as a key information intermediary-differently impacts their } \\
\text { effectiveness. }\end{array}$ \\
\hline
\end{tabular}




\title{
Signal Strength, Media Attention, and Resource Mobilization: Evidence from New Private Equity Firms
}

\author{
Tom Vanacker \\ Ghent University; University of Exeter \\ TomR.Vanacker@UGent.be \\ Daniel P. Forbes \\ University of Minnesota \\ forbe010@umn.edu \\ Mirjam Knockaert \\ Ghent University; Technical University of Munich \\ Mirjam.Knockaert@UGent.be \\ Sophie Manigart \\ Vlerick Business School; Ghent University \\ sophie.manigart@vlerick.com \\ Forthcoming in Academy of Management Journal \\ DOI: $10.5465 / \mathrm{amj} .2018 .0356$
}

\begin{abstract}
Acknowledgments. We thank the Editor and three anonymous $A M J$ reviewers for their excellent feedback. Prior drafts of this paper benefited from presentations at the Academy of Management Conference, the Babson College Entrepreneurship Research Conference and the 3rd Entrepreneurial Finance Conference. We further thank Maw-Der Foo, Benjamin Hammer, Andrew Winton, and seminar participants at Erasmus University Rotterdam, Maastricht University, SKEMA Business School, Technical University of Munich, University of Bergamo and University of St. Gallen for constructive feedback on prior drafts of this paper. We also thank Preqin for access to their database and additional information provision. The research was supported by the Richard M. Schulze Family Foundation.
\end{abstract}




\title{
SIGNAL STRENGTH, MEDIA ATTENTION, AND RESOURCE MOBILIZATION: EVIDENCE FROM NEW PRIVATE EQUITY FIRMS
}

\begin{abstract}
Past research has shown that new firms can facilitate resource mobilization by signaling their unobservable quality to prospective resource providers. However, we know less about situations in which firms convey multiple signals of different strengths-i.e., signals that are more or less correlated with unobservable firm quality. Building on a sociocognitive perspective, we propose that prospective resource providers respond differently to signals of different strengths and that the effectiveness of signals, especially weak signals, will be contingent on the media attention new firms receive. Empirically, we conduct a longitudinal analysis examining the ability of new private equity (PE) firms to raise a follow-on fund. Consistent with our theory, we find that unrealized performance, a relatively weak signal, positively influences fundraising. But we fail to find statistical evidence that its effect is weaker than that of realized performance, a relatively strong signal. Further, media attention strengthens the relationship between unrealized performance and fundraising, but media attention exerts less impact on the relationship between realized performance and fundraising. Taken together, our findings deepen our understanding of how new firms can mobilize resources with signals of different strengths and of how the media — as a key information intermediary-differently impacts their effectiveness.
\end{abstract}

\section{INTRODUCTION}

Resource mobilization is a challenge for all firms, but this challenge is especially acute for new firms (Clough et al., 2019; Stinchcombe, 1965). One reason is that new firms face high levels of uncertainty about their future prospects (Sanders and Boivie, 2004). Another reason is that large information asymmetries between new firms of uncertain quality and prospective resource providers make the latter reluctant to contribute their valuable and scarce resources to the former (Akerlof, 1970; Stuart et al., 1999). Despite these heightened challenges, new firms must find ways to mobilize resources to ensure their survival (Aldrich and Ruef, 2006).

One influential perspective that addresses this resource mobilization challenge is signaling theory (Spence, 1973; 2002), which holds that high-quality firms signal their unobservable quality with observable attributes that are costly or difficult to imitate by lowquality firms. Management scholars generally invoke variants of signaling theory that are 
broader and less formal than the traditional economic perspective associated with the "Spencian" approach. As Clough and colleagues observe (2011: 248), "the term 'signal' describes any informational characteristic that credibly indicates [a firm's] underlying quality". For example, research in management shows that firms can signal their quality with board characteristics (Certo, 2003), team characteristics (Higgins and Gulati, 2006; Plummer et al., 2016), early accomplishments (Hallen, 2008) and endorsement relationships (Gulati and Higgins, 2003; Plummer et al., 2016; Reuer et al., 2012; Ozmel et al., 2013; Stuart et al., 1999), among other attributes, to convince prospective resource providers to contribute their scarce resources to these firms (See also Bergh et al. (2014) and Connelly et al. (2011) for reviews of the signaling literature in management).

At the same time, less is known about situations in which firms convey multiple simultaneous signals (Drover et al., 2018; Steigenberger and Wilhelm, 2018). As Drover and colleagues (2018: 210) observe, "signaling theory research, as formulated by Spence and those who followed, does not adequately explain how individuals allocate attention to or interpret multiple signals". Among the issues that arise in connection with multiple signals, for example, is that signals may be stronger or weaker depending on "the extent to which the signal is correlated with unobservable quality" (Connelly et al., 2011: 53). However, past research has not explained how prospective resource providers respond to multiple simultaneous signals of different strengths.

This is an important issue for several reasons. First, there is growing theoretical recognition that signal transmission is not an "automatic" process but instead requires that signals be received and processed by signal receivers operating in complex information environments (Bergh et al., 2014; Bitektine, 2011; Drover et al., 2018). For example, "most real- 
world settings feature a wild assortment of possible stimuli and cues" (Felin et al., 2017: 1056), and within such contexts the same firm may convey multiple signals (Stern et al., 2014; Plummer et al., 2016). In light of these considerations, there is a need for empirical studies to account for a broader range of informational cues than have historically been considered (Jensen et al., 2012; Steigenberger and Wilhelm, 2018).

Second, there is a need to account more fully for variations in the way receivers attend to and interpret specific signals owing to differences among signals as well the influence exerted by elements of the signaling environment or context (Connelly et al., 2011; Kim and Jensen, 2014). For example, while signaling research has generally focused on signals that are argued to be strong, a more limited set of research has argued that signals are not uniformly strong but rather exist on a continuum of varying strengths (e.g., Gemser et al., 2008; Gulati and Higgins, 2003; Park and Mezias, 2005). Nevertheless, Bergh et al. (2014) observed that none of the studies in their extensive literature review provided direct evidence of signal strength. Moreover, as Connelly and colleagues (2011: 62) observed, the "signaling environment is on the whole an underresearched aspect of signaling theory" even though there is evidence that managers' attention and decision making can be affected by various aspects of their information environments (Hoffman and Ocasio, 2001; Shroff et al., 2013).

Third, signals of varying strengths are likely to be especially important to account for in entrepreneurial settings, where new firms - owing to their newness and uncertainty — often find themselves without the historical and external bases of evidence that can signal the quality of more established firms (Petkova, 2012). Indeed, many new firms find themselves in a catch-22 situation: prominent affiliates could serve as a strong signal, for example, but such affiliates themselves rely on signals to decide which new firms to contribute their scarce resources to 
(Martens et al., 2007). To the extent that weaker signals may represent an avenue of escape from such situations, it behooves us to better understand how resource providers attend to weaker signals.

In this paper, we advance the management literature on signaling by new firms by examining how multiple simultaneous signals of different strengths impact resource provision decisions. Bergh and colleagues (2014: 1347) proposed that in order to shed light on such issues, scholars "could integrate ideas from signaling theory with other information processing perspectives". Consistent with this advice, we adopt a sociocognitive perspective (Bitektine, 2011; Pollock and Rindova, 2003), which, "is ... rooted in a bounded rationality view of strategic decision makers who satisfy rather than optimize performance outcomes, as they rely on heuristics and cognitive simplifications to cope with uncertainty and cognitive overload" (Rindova et al., 2012: 5). Drawing on this perspective, we propose that weak signals help new firms attract resources from resource providers but that weak signals will be less impactful in doing so than strong signals. Moreover, building on past sociocognitive work that has highlighted the influence of information intermediaries on evaluators' attention and evaluations (e.g., Petkova et al., 2013; Pollock and Rindova, 2003; Pollock et al., 2008; Rindova et al., 2012), we propose that the media attention new firms receive will strengthen the relationship between weak signals and resource attraction, but that media attention will exert less impact on the effectiveness of strong signals. Thus, whereas past research has tended to overlook or downplay the social context in which signaling occurs (Steigenberger and Wilhelm, 2018), our approach explores whether and how characteristics of the signaling environment may influence the effectiveness of signals. 
We investigate our claims in the context of new private equity (PE) firms that manage their first-time fund but need to raise a follow-on fund to remain in business, given the limited lifetime of PE funds. This context is replete with information asymmetry and uncertainty (Balboa and Marti, 2007; Sahlman, 1990), and-unsurprisingly-many new PE firms fail to raise a second fund (Rider and Swaminathan, 2012). Within this context, we focus on performancerelated signals: specifically, the realized and unrealized performance of the PE firms' first-time funds. Below, we argue and show that both types of performance signals differ in signal strength, with unrealized performance representing a weaker signal and realized performance representing a stronger signal. Unlike some other signals, such as those that reference a new firm's social ties or human capital, which require resource providers to draw inferences linking some factor or set of factors with the firm's capacity to perform over time, these signals speak directly to the new firm's own capacity to perform, which is the consideration of most interest to investors and many other resource providers.

We use longitudinal data to investigate the ability of 205 first-time PE funds to raise a follow-on fund. As expected, we find that higher unrealized performance fosters fundraising. Although qualitative comparisons indicate that weak signals are indeed economically less impactful than strong signals, we fail to find statistical evidence that the effect of unrealized performance is weaker than the effect of realized performance. Further, consistent with our expectations, we find that the effect of unrealized performance on fundraising is significantly stronger for PE firms that attract more media attention, whereas media attention is less impactful for the relationship between realized performance and fundraising.

Our primary contribution is to the management literature on how new firms use signaling to attract resources. Empirically, we add to this literature by providing evidence that firms 
convey signals of different strengths, that weaker signals can also aid in resource attraction, and that information intermediaries (e.g., the media) can amplify the effectiveness of weaker signals. Theoretically, we enrich this literature by proposing sociocognitive explanations for these effects that complement and extend recent management research on how new firms' resource attraction prospects are shaped by the ways in which resource providers receive and process information (Hallen and Pahnke, 2016; Steigenberger and Wilhelm, 2018; Vanacker and Forbes, 2016).

\section{THE RESEARCH CONTEXT: PRIVATE EQUITY FUNDRAISING}

PE firms, including venture capital (VC) and buyout firms, are specialized financial intermediaries which usually invest in the equity of privately held companies (Cumming and Walz, 2010; Wright and Robbie, 1998). Our study focuses on independent PE firms, which are not linked to any parent organization, such as corporate PE funds. We do so because independent PE firms have to raise funds from external investors while corporate PE funds get their funding from parent companies, making resource mobilization inherently different.

Independent PE firms are typically organized as limited liability partnerships, whereby general partners (GPs) manage the PE funds and limited partners (LPs) provide the funds. LPs typically include institutional investors, such as banks, insurance companies, and pension funds as well as governments, sovereign wealth funds, corporations, family offices, and private individuals (Sahlman, 1990; Sammut, 2011). The legal life of most PE funds is set at 10 years, implying that the aim is to sell or exit funds' assets and distribute the proceeds to LPs before the 10-year time period, although provisions are often included to extend the life of funds by two years (Dimov and Gedajlovic, 2010; Sahlman, 1990). Each fund moves through various stages (Sammut, 2011). During the investment period stage, usually the first four years after establishing a fund, investment targets are sought and the investment portfolio is formed. During the maturity stage, some three to seven years after establishing a fund, follow-on financing 
rounds may be provided to the portfolio companies in order to further support their growth. Finally, in the harvest or liquidation stage, generally from five years after establishing a fund to the end of a fund's life, GPs are focused on exiting their investments through IPOs, trade sales or secondary buyouts, thereby turning their illiquid stakes in privately held companies into realized returns and returning the proceeds to the LPs.

Given the finite lifetime of independent PE funds, GPs need to raise new funds from LPs on a regular basis to continue their activities. GPs typically engage in fundraising activities to establish a new fund some three to five years after the start of their previous fund (Sahlman, 1990), which corresponds with the end of the previous fund's investment period (Rider and Swaminathan, 2012). Failing to find sufficient investors for a follow-on fund will prevent GPs from continuing their investment activities in new portfolio companies and will eventually lead to the end of the PE firm (Freeman, 2005). A large percentage of PE firms fail to raise a second fund and thereby eventually "exit" the market or experience mortality (Rider and Swaminathan, 2012). This high mortality rate is not surprising because the relationship between PE managers and their (prospective) capital providers is characterized by significant information asymmetries (Balboa and Marti, 2007; Sahlman, 1990). The ultimate performance of a PE fund is only known once all investments have been exited and the cash is returned to investors, at the end of the lifetime of the fund (Cumming and Walz, 2010). This situation is particularly problematic for new PE firms, which need to raise follow-on funds at the end of the investment period of their first fund, often well before having exited their investments and hence before having demonstrated significant realized performance. Overall, the PE firm setting allows us to examine resource acquisition in a setting where information asymmetry problems between new firms and prospective resource providers are particularly severe. 
We focus on different performance-related signals (Fombrun and Shanley, 1990) that could reduce prospective capital providers' informational disadvantages and uncertainty with respect to the quality of new PE firms. Performance-related signals can relate to both realized and unrealized performance. Realized performance-i.e., performance to which a definitive value has been assigned - has been shown to be a strong predictor of a firm's ability to attract additional resources (Cumming et al., 2005; Hallen, 2008). Past realized performance is also a strong predictor of future performance (Bromiley, 1991) and thus represents a strong signal. In our context, PE managers of first-time funds realize returns by exiting their investments in private companies. Successful exits signal PE managers are good "scouts" and "coaches" (Baum and Silverman, 2004), and these exits are extremely difficult to imitate by low ability PE managers. Consequently, realized performance is also expected to be a strong signal within the PE context.

However, a track record of realized performance is often unavailable for new PE firms (even those of high quality). PE firms therefore also signal their "unrealized performance", which refers to their valuation of equity stakes that are still to be exited (potentially many years ahead). These valuations rely heavily on estimates, forecasts, or promises; they are determined by the GPs and usually certified by external auditors. It is undeniably harder for PE firms with poor investments to present good unrealized performance than it is for a PE firm with good investments, which makes unrealized performance a signal as well. Still, unrealized performance is expected to be a weaker signal than realized performance. Indeed, unrealized performance remains a specific form of non-binding communication by PE managers that is inevitably subjective. For example, Jenkinson and colleagues (2013) identified significant differences in the independently reported unrealized performance by separate fund managers, who jointly invested 
in the same company. Further, research has shown that PE managers' valuations of private portfolio companies that are not yet exited are positively biased, especially when they are in fundraising mode (Cumming and Walz, 2010). Several LPs we interviewed confirmed these insights from previous research. Below, we will use insights and quotes from these interviews to substantiate and enrich our theoretical claims. More information on the interviews can be found in Appendix 1.

\section{THEORY AND HYPOTHESES}

To understand how prospective resource providers assess unobservable firm quality to inform their resource provision decisions in an environment characterized by informational asymmetry and uncertainty, scholars have often drawn on signaling theory (Connelly et al., 2011; Spence, 1973). Within the signaling literature, scholars have tended to implicitly assume that the specific signal under investigation is strong. However, some recent literature calls attention to the possibility that firms may convey multiple signals (Drover et al., 2018).

For example, research has shown that investors consider multiple firm actions or attributes in deciding whether to provide resources to a firm (Lee, 2001; Stern et al., 2014). Consideration of multiple signals raises the question of whether signals sent simultaneously by a firm differ in strength. Past research has argued that signal strength can vary over time (e.g., Gulati and Higgins, 2003; Park and Mezias, 2005), but "empirical research comparing different types of quality signals remains scarce" (Gemser et al. 2008: 45). The question of how resource providers respond to multiple signals of varying strengths is especially salient in entrepreneurial settings, where conditions of uncertainty and information asymmetry are particularly acute. For example, new firms often lack the track records and external endorsements through which more established firms often signal their quality (Petkova, 2012). Accordingly, we ask whether and when signals of different strengths influence resource attraction by new ventures. 
Although the origins of signaling theory lie in economics (Spence, 1973), management scholars have adopted a broader set of theoretical assumptions regarding the way signal receivers process information, thereby "circumventing the limitation of signaling theory, which clearly sees actors as rational agents" (Bergh et al., 2014: 1354). For example, management scholars have called attention to the fact that signal receivers do not perceive all signals equally. This observation is particularly true in entrepreneurial settings, since "there are many more early stage, than late stage, firms in which to invest, so potential investors need to process a wider range of information" (Plummer et al., 2016: 1586). Moreover, in entrepreneurial settings, careful consideration of individual investment alternatives is costly and time-consuming (Wiltbank, 2005). Similarly, in contrast to the traditional assumption that "signals are noticed and/or attended to by almost everyone" (Drover et al., 2018: 210), management scholars have begun to explore aspects of the signaling environment that may "make signals more or less observable" (Connelly et al., 2011: 62). Taken together, these considerations underscore the limits of the traditional, "mechanistic understanding of signaling" (Connelly et al, 2011: 61), and point towards the need for a broader theoretical perspective that pays more attention to the process by which signal receivers notice, use, and interpret signals.

In response to this need, we adopt a sociocognitive perspective on the signaling process (e.g., Rindova et al., 2012). This perspective has two key implications. First, we maintain that new firms' signals do indeed matter to resource providers but that resource providers tend to gather and analyze information in ways that reflect the constraints they face (Gavetti et al., 2007; Hallen and Pahnke, 2016; Vanacker and Forbes, 2016). Specifically, we maintain that prospective capital providers in new PE firms, like decision-makers in many other contexts, are boundedly rational and, therefore, "tend to make decisions on the basis of effort-preserving, but 
sometimes fallible, cognitive heuristics" (Hallen and Pahnke, 2016: 1537). Second, in contrast to the conventional approach to signaling, which tends to focus exclusively on the interaction between senders and receivers of signals, the sociocognitive perspective maintains that the social context in which receivers are situated can influence whether and how they attend to specific signals (Hoffman and Ocasio, 2001; Rindova et al., 2012). More specifically, this approach highlights the important role played by information intermediaries, such as the media, in affecting the way decision-makers attend to and process specific signals (Pollock and Rindova, 2003; Rindova et al., 2012; Zuckerman, 1999).

\section{Signals of Different Strengths and Fundraising}

The idea that strong signals facilitate resource mobilization is well-established (Hallen, 2008). Also, in our context of PE fundraising, there is considerable evidence that realized performance, a strong signal, positively influences fundraising success (e.g., Cumming et al., 2005). Thus, we start by theorizing about the impact of unrealized performance, a comparatively weak signal, on the likelihood that first-time PE funds raise a follow-on fund. We propose that higher unrealized performance will positively influence prospective capital providers' resource provision decisions.

One reason higher unrealized performance is likely to influence prospective capital providers is that it can enable firms to call attention to themselves and thereby enter into investors" "consideration set". Prospective capital providers are generally faced with many alternatives from which to choose as well as with constraints in terms of staffing and time. Accordingly, they must simplify their investment decisions with a "consider-then-choose" decision process. This process entails that prospective capital providers will first identify a subset of firms, the "consideration set" (Jensen and Roy, 2008), for further evaluation, and then choose from among the firms in this set. As Petkova et al. (2013: 866) note: "being considered, 
therefore, precedes being evaluated". The importance of entering into a consideration set has been illustrated in multiple markets, including consumer (e.g., Hauser, 2014), labor (e.g., Williamson, 2000), and financial markets (e.g., Merton, 1987; Petkova et al., 2013; Pollock et al., 2008). In financial markets, for instance, Merton (1987) suggests that investors' consideration set includes firms that have caught their limited attention and that they only evaluate such firms.

In our context, where many alternative PE firms exist, it is unlikely that any one prospective capital provider will actively consider all investment options. LPs generally use commercial databases (such as Preqin) in conjunction with other sources, which universally include records of performance, to identify the universe of possible investment options (e.g., Preqin, 2014; Boivin et al., 2019). This claim is also confirmed by our interviewees. For the reasons explained above, LPs cannot include all these PE firms in their consideration set. We expect that prospective capital providers will rely on signals to help identify new PE firms that merit closer attention. Thus, unrealized performance is likely to serve as a signal that can draw the attention of prospective resource providers to new PE firms.

In particular, we expect that new PE firms with higher levels of unrealized performance will be more likely to be drawn into prospective capital providers' investment consideration set. We maintain this expectation even as we acknowledge that unrealized performance is a relatively weak signal (compared to realized performance). One reason for our expectation is that even for new PE firms of high quality, much of their value will be unrealized at the time of their fundraising. Our interviews indeed indicate that LPs use performance data to identify firms that require further investigation and that unrealized performance affects which firms enter into the consideration set. As one LP noted: "If a firm has realized performance, it helps. However, 
unrealized performance is not to be neglected as many firms approach us three or four years after their first fundraising. At that time, it is difficult for them to have exits, so we consider where firms rank in terms of unrealized performance". Another LP confirmed: "There must be some indication of performance, either realized or unrealized. Having realized some hard exits helps but is not required ... all these things are not carved in stone".

A second reason higher unrealized performance is likely to influence prospective capital providers is that it may influence their evaluation processes as well. The unrealized performance of first-time funds is likely to function as an "anchor" in these evaluation processes such that PE funds with higher levels of unrealized performance will induce decision-makers to arrive at more favorable conclusions about the prospects of these funds. Indeed, there is evidence that information cues provided early in an evaluation process can produce an anchoring effect, a "biased estimate toward an arbitrary value considered by judges before making a numerical estimate" (Strack and Mussweiler, 1997: 437). This effect has been shown to operate in connection with valuation and performance tasks (Ariely et al., 2003; Thorsteinson et al., 2008), and the effect has even been observed with expert evaluators and in situations in which alternative information is abundant. For instance, Northcraft and Neale (1987) show that manipulated listing prices anchor values assigned to real estate properties, even for expert real estate agents who received a detailed information package and toured the property.

Clearly, PE managers cannot just put any value on their portfolio of unrealized investments. These are typically audited by qualified external auditors (Barber and Yasuda, 2017) and LPs conduct their own detailed due diligence on them. For example, the LPs we interviewed described assigning their own valuations based upon talks with portfolio companies and other industry contacts, independent auditor valuations, or a comparison of the unrealized 
valuation by one GP with that of another GP in case of syndicated investments. Awareness of this due diligence process, as well as broader reputational concerns, are expected to provide some discipline to PE managers that report their unrealized performance.

However, due diligence is incapable of truly "verifying" unrealized performance (Kerr et al., 2014), and a good valuation is not a point estimate but rather a credible valuation range (Damodaran, 2006) from which PE managers can still select a value from the upper bound. Consistent with these ideas, there is evidence that PE managers provide unrealized performance estimates that are on average positively biased, especially when they are in fundraising mode (Barber and Yasuda, 2017; Cumming and Walz, 2010). One LP we interviewed noted: "It does happen that, upon fundraising, the value of the unrealized portfolio is somewhat inflated, but GPs also realize they have to be careful and not overdo it". Overall, when PE managers provide higher unrealized performance estimates that are within a credibility window, these are likely to serve as an anchor and prompt LPs to arrive at more favorable valuations as well. In fact, Northcraft and Neale (1987) show that even when an anchor is outside a credibility window, it can still positively influence the valuations of experts. ${ }^{1}$ Thus,

Hypothesis 1. Higher unrealized performance of first-time funds will increase the likelihood of raising a follow-on fund.

We have argued that unrealized performance, a weaker signal, will positively influence investors' resource provision decisions. Past research has also established that realized performance, a stronger signal, will positively influence investors' resource provision decisions (Cumming et al., 2005; Hallen, 2008). Below, we propose that prospective resource providers

\footnotetext{
${ }^{1}$ One may wonder why expert decision-makers do not learn (enough) from their mistakes in the past. There is evidence that even experts often do not learn from their fallible judgments because of other cognitive biases or limitations. Zacharakis and Shepherd (2001), for instance, argue that delayed feedback combined with recall biases and decision-makers' tendency to engage in post hoc rationalizations are likely to constrain learning. In our context, unrealized performance can indeed take many years to turn into realized performance, making some of these problems more acute. Northcarft and Neale (1987) further show that experts are less likely to admit (or to understand) that they use anchors in their decision making, relative to amateurs.
} 
will differently attend to and evaluate these signals of different strengths, such that the impact of the weaker signal, i.e. unrealized performance, on fundraising will be weaker than that of the stronger signal, i.e. realized performance. ${ }^{2}$

One reason is that some demonstration of realized performance is a highly sought-after characteristic of new PE funds given its higher signal strength relative to unrealized performance. An LP told us "We prefer, of course, hard exits, so distributions [i.e., realized performance] instead of just a high residual value [i.e., unrealized performance]". Hence, higher levels of realized performance are likely to be especially influential in bringing new PE firms into the consideration set of prospective capital providers. When discussing how LPs attend to the performance of first-time PE funds, one LP indicated: "if they already have a 'winner' then it's an easy one". Consistent with these ideas, research in marketing has shown that while there are many different decision rules that may guide the formation of consideration sets, "topranked" characteristics (i.e., realized performance in this context) are especially influential in doing so (e.g., Hauser, 2014).

A second reason is that during the evaluation or due diligence phase, realized performance can be easily verified because it is factual data based upon hard outcomes, as opposed to expectations or estimates. Realized performance is a direct indicator of a firm's early accomplishments (e.g., Hallen, 2008) and, more specifically, in our context, it shows PE managers' ability to select promising companies, build these companies and exit them. While there is always a possibility for honest disagreement with respect to the unrealized performance of first-time funds, this is not the case for their realized performance. Thus,

Hypothesis 2. The impact of higher unrealized performance of first-time funds on the likelihood of raising a follow-on fund will be weaker than the impact of higher realized performance.

\footnotetext{
${ }^{2}$ Next to comparing the effectiveness of signals of different strength, one may also wonder whether these signals interact. Past work shows that independent signals do interact (e.g., Plummer et al., 2016; Ozmel et al., 2013). However, our signals are not independent. Specifically, within PE funds, when realized performance increases, all else equal, unrealized performance should decrease. Moreover, within PE funds, realized performance can only remain stable or increase over time. Consequently, combinations where both realized performance and unrealized performance increase or decrease are rare to impossible. These considerations explain why we do not hypothesize an interaction effect. We did run models that include an interaction effect between unrealized performance and realized performance but the interaction effect was not significant.
} 


\section{The Moderating Influence of Media Attention}

So far, we have assumed that prospective resource providers respond to signals of different strengths independently of the social context firms are in. However, consistent with our sociocognitive perspective, we recognize that aspects of the signaling environment can also influence the effectiveness with which signals are transmitted (Connelly et al., 2011). Among the most important elements of the environment are those that are liable to affect the observability of signals, or the "degree to which a signal is easily attended to by an organizational outsider" (Drover et al., 2018: 217). Owing to the central role that media sources play as information intermediaries in many markets, media attention has been recognized as a key environmental factor that can affect managers' decisions (Rindova et al., 2012; Shroff et al., 2013).

New ventures with higher levels of media attention are more likely to become known by prospective capital providers (Pollock and Rindova, 2003; Vanacker and Forbes, 2016). "Being known" is often viewed as a crucial factor that helps firms enter into resource providers' consideration set (Williamson, 2000). Consistent with this claim, one LP we interviewed remarked, "if the name sounds familiar and if we have read about them [in the media]... then the file is more likely to be analyzed". Accordingly, we argue that the attention new firms receive from the media will strengthen the impact of these firms' unrealized performance on their ability to mobilize resources.

The expectation that new PE firms with higher unrealized performance will be more likely to enter into prospective resource providers' consideration set and raise a second fund, as we discussed before, is predicated on the assumption that the signals sent by each individual PE firm are equally likely to be received and used by resource providers: that "if a signal is provided, the appropriate actor will naturally attend to it and use it" (Pollock and Gulati, 2007: 340). Nevertheless, as Pollock and Gulati (2007: 340) further highlight, much "less attention has 
been paid to how ... signals increase a firm's likelihood of inclusion in the 'consideration sets"” of resource providers. Thus, even in cases where new PE firms report high levels of unrealized performance, those performance signals could remain unnoticed or unused by prospective capital providers, especially if the reporting firms are new PE firms that are less known. Media coverage of the reporting PE firms may mitigate this risk.

As many PE firms report unrealized performance, LPs cannot investigate in detail all firms that report higher unrealized performance. The media attention new firms receive might help them (and their signals) to stand out from the crowd (Petkova, 2012). Thus, we anticipate that prospective capital providers will be more likely to notice and use the high unrealized performance signals of new PE firms that attract more media attention. Conversely, claims of high unrealized performance by new PE firms that attract less media attention are more likely to remain unnoticed or unused by prospective capital providers, given their cognitive limitations.

At the same time, we expect that firms' media attention will strengthen the "anchoring" effects we discussed earlier. Firms that attract more media attention will be viewed as more legitimate (e.g., Petkova et al., 2013; Pollock and Rindova, 2003). This effect is consistent with the well-established psychological "mere exposure effect" (Pollock and Rindova, 2003). This effect holds that the mere repeated exposure of people to a stimulus object (e.g., a firm) is a sufficient condition for them to make the stimulus more liked (Harrison 1977, Zajonc 1968) and thus more legitimate. The anchoring literature highlights that a more legitimate source of information (i.e., the firms legitimized by the media attention they received) can create stronger anchoring effects (van Exel et al., 2006). Thus,

Hypothesis 3. Media attention will positively moderate the relationship between higher unrealized performance of first-time funds and the likelihood of raising a follow-on fund. 
Finally, media attention is likely to exert a stronger moderating influence on the effect of unrealized performance, than on the effect of realized performance, on fundraising. As with unrealized performance, media attention may help new PE firms to draw LPs' attention to their higher realized performance signals and as such become more likely to enter into investors' consideration set (e.g., Pollock and Gulati, 2007), especially in a setting where many PE firms (including established firms) convey reports of realized performance. However, contrary to the role of media attention in strengthening the anchoring effect of unrealized performance in the evaluation phase, realized performance encompasses definitive values, as opposed to the estimated values represented by unrealized performance. Consequently, when evaluating realized performance, it should not a priori matter whether realized performance is communicated by a firm that is viewed as more or less legitimate as a consequence of its media attention. Thus,

Hypothesis 4. Media attention will more positively moderate the relationship between higher unrealized performance of first-time funds and the likelihood of raising a followon fund than the relationship between realized performance and the likelihood of raising a follow-on fund.

\section{METHODS}

\section{Data and Sample}

The data for this study come from the Preqin database, which combines fundraising and performance data for a variety of investment funds, including VC, buyout, real estate and hedge funds. In this study, we consider the two major types of PE funds, namely VC and buyout funds (Wright and Robbie, 1998). Preqin's fund performance database covers over 5,800 funds managed by some 1,900 PE firms from all over the world. Preqin indicates their database includes over $60 \%$ of all capital raised historically. Preqin collects its data through direct engagement with industry participants (i.e., GPs and LPs), through Freedom of Information Laws, and by monitoring other data sources, including regulatory filings, press releases, news, 
and websites. Many Preqin subscribers are institutional investors, who use the database to search for investment opportunities. For instance, the Preqin investor network includes over 7,800 investment professionals, and there are over 20,000 logins monthly from these investors. ${ }^{3}$ Studies into the Preqin performance data indicate that they are current, do not appear to be selected, and are unlikely affected by appreciable bias (e.g., Harris et al., 2014; Kaplan and Lerner, 2016).

We selected all new PE firms that raised their first fund between 1999 and 2007 and collected data for these firms/funds up to December 2017. New PE firms that raised their first fund after 2007 are not included in our data for two reasons. First, we wanted to ensure that all PE firms had enough time to raise a second fund over the timeframe of our study. ${ }^{4} \mathrm{Second}$, we required data on the eventual realized performance of first-time funds at the end of their economic life, which typically is 10 years after their establishment, to confirm that our independent variables are signals characterized by different signal strength. This selection resulted in a dataset of 321 new PE firms. We incorporated measures for each firm-year entry between 1999 and 2017. Firm-year observations were censored for years where new PE firms were no longer "at risk" of raising a second fund, that is, those years after PE firms raised a follow-on fund or when the age of the PE firm's initial fund exceeds 13 years and no follow-on fund was raised. ${ }^{5}$ We removed those firm-year entries for which essential data, including

3 Detailed information on Preqin is available in its "private capital performance data guide" at: http://docs.preqin.com/reports/Preqin-Private-Capital-Performance-Data-Guide.pdf

${ }^{4}$ For those PE firms that raised a follow-on fund, the average (median) PE firm required 4 (3) years to do so, while one PE firm required 11 years.

${ }^{5}$ This 13 years cut-off covers the typical 10 years economic life time of funds and common provisions to extend their life with an additional two years. PE firms are unlikely to be at risk of raising a follow-on fund after the life of their first fund. Our results remain robust without employing this exclusion criterion. 
performance data, was missing. This step resulted in a final sample of 205 new PE firms and 1,057 firm-year observations. ${ }^{6}$

\section{Variables}

Our dependent variable, raising a follow-on fund, is dummy coded. The dummy variable equals 1 when a new PE firm $i$ raises a follow-on fund in a focal year $t$, and 0 otherwise. This variable is theoretically relevant because it directly relates to the ability of PE managers to overcome resource mobilization challenges. More specifically, it captures the ability of PE managers to raise new financial resources from prospective capital providers and thereby remain in business; a challenge that many PE managers cannot overcome given significant information asymmetry and uncertainty in this context (Rider and Swaminathan, 2012). Our decision to focus on the ability to raise a follow-on fund - rather than, for example, on the size of the follow-on fund - is also motivated by two additional observations. First, the size of the follow-on fund can only be observed for the "successful" PE firms that raised a follow-on fund. Second, raising a follow-on fund is critical for all PE managers, who need to raise new funds on a regular basis to continue their activities given the limited life of PE funds. However, not all PE managers - such as those managing specialized, "boutique" PE firms — strive to raise larger funds. ${ }^{7}$

Our independent variables include unrealized performance and realized performance. Preqin provides guidelines to GPs in order to ensure consistent performance reporting. All performance metrics are net of fees and carried interest so that these metrics reflect net-to-LP returns. ${ }^{8}$

\footnotetext{
${ }^{6}$ This drop out is common when using standard PE databases. For instance, in Zarutskie (2010) the sample size decreases from 318 to 222 first-time VC funds when additional data is required for the analysis.

${ }^{7}$ For those PE managers that raised a second fund, we find that the correlation between the size of the first fund and the size of the second fund is 0.92 .

${ }^{8}$ There is the possibility that retrospective edits will be made to the performance data but only when errors come to light or GPs wish to amend what they previously reported. However, Preqin has confirmed that such backwards revisions of the data are extremely rare.
} 
Unrealized performance is defined as the valuation of unrealized investments and is reported as a percentage of called capital in a focal year $t$ of the first-time fund. The value of unrealized investments represents an estimate of the amount at which an asset could be acquired or sold in a transaction; however, it represents uncertain returns on paper, as actual returns are only realized at exit, which might be many years away. Values of unrealized performance range between $0 \%$ and $1,782 \%$, with a mean value of $74.26 \%$ (S.D. $=88.14 \%$ ). We take the natural logarithm of unrealized performance (e.g., Shaver, 2007), because of the decreasing value of an additional unit of unrealized performance. This transformation also has the advantage that it decreases the probability that extreme observations will affect the findings.

Realized performance is defined as distributions to the LPs up to a focal year $t$ as a percentage of called capital of the first-time fund. Realized performance represents the returns that LP investors in a fund receive (Wright and Robbie, 1998). It is the income and capital (less expenses and liabilities) realized from exiting investments by way of an initial public offering, acquisition or another form of exit. Values of realized performance range between $0 \%$ and $1,782 \%$, with a mean value of $49.04 \%$ (S.D. $=108.45 \%$ ). As with unrealized performance, we take the natural logarithm of realized performance.

We construct a moderator variable capturing the media attention towards PE firms managing their first fund, using the ProQuest Global Newsstream database. This database covers over 2,800 news sources including newspapers, news websites, and blogs from leading publishers. ProQuest provides one of the largest collections of news from the US, Canada, Europe, Africa, Asia, Latin America, and Australia. ProQuest incorporates the US Newsstream, Canadian Newsstream, and International Newsstream databases. It also includes the Factiva database. The database is commonly used to construct measures of media attention (e.g., Bednar, 


\footnotetext{
${ }^{9}$ Consistent with our theorizing, we focus on media attention, which is important in its own right (e.g., Petkova et al., 2013). We acknowledge that media attention may also have a specific tenor (e.g., positive or negative).
However, in line with the observations made by Dimov et al. (2007), media coverage in the PE context can be al., 2013). We acknowledge that media attention may also have a specific tenor (e.g., positive or negative).
However, in line with the observations made by Dimov et al. (2007), media coverage in the PE context can be expected to be rather neutral. In order to verify this assumption, we carefully examined a random sample of 50 articles and found these articles to be largely descriptive and neutral.

${ }^{10}$ For all variables where we include interaction terms we mean centered the variables (e.g., Kutner et al., 2005).
} attention as the number of citations in ProQuest to a specific PE firm in $t-1$. By doing so, we avoid the risk that our measure includes media coverage as a consequence of PE firms raising a follow-on fund. PE firm media attention ranges between 0 and 495, with a mean value of 9.5. We take the natural logarithm of media attention because of the decreasing value of an additional unit of media attention (e.g., Pollock and Rindova, 2003). ${ }^{9}$ We further include the interactions between unrealized performance and media attention and realized performance and media attention. ${ }^{10}$

We control for time-varying PE firm/fund characteristics. Fund age is defined as the difference between $t$ and the vintage year of the first fund. We also include fund age squared to control for a possible non-linear relationship between firm age and fundraising (e.g., Gompers and Lerner, 1998). Further, PE fund age controls for the fact that unrealized and realized performance are not equally important throughout the lifecycle of a PE fund. A young PE fund has by design a low unrealized and realized performance because the companies in the portfolio will not have had the time to create value yet and the number of realized investments (or exits) will be limited. As a PE fund ages, its realized value will increase monotonously over time as more investments are exited. While its unrealized performance may increase in a first phase due to the increase in value of the companies in its portfolio, it will decrease at the end of the life of the fund, as most investments will be exited and generate realized value; little unrealized value will thereby remain in the fund. Called capital is defined as the proportion of capital that has 
been called on the total amount committed. Controlling for called capital is relevant as LPs typically do not invest the total amount committed at the start of a PE fund. Instead, GPs will call fractions of the committed capital when needed for investment purposes. When PE fund managers experience difficulties in finding interesting investment projects and called capital thus remains low, PE managers may be constrained in raising a second fund.

To control for macroeconomic evolutions, we include a time-varying ratio of $P E$ raised on GDP. This variable allows to control for the cyclical nature of fundraising in PE markets (Gompers and Lerner, 1998). Specifically, we calculated the ratio of PE raised to GDP for the US economy. We use statistics for the US because the bulk of PE firms in our sample are located in the US. Moreover, PE markets in other regions around the world typically follow the evolution of fundraising in the US market. We further include the yearly S\&P500 return to control for the public equity market conditions. Finally, we include calendar year dummies to further control for the effects of any general economic event or trend.

We also collected data on first-time PE fund characteristics that do not vary over time. These data are used throughout our descriptive statistics and some regressions but are not incorporated in our main regressions because, as we detail below, these models already control for all stable PE firm characteristics by including PE firm fixed effects. We make a distinction between VC and buyout funds. We dummy code venture capital equal to 1 when the PE fund is a VC fund, and 0 when it is a buyout fund. Fund size is calculated as the natural logarithm of total capital raised by the PE firm (in million, dollars) for its first-time fund. We also capture the primary geographical investment focus of the first-time PE funds. We make a broad distinction between a primary geographical investment focus in the US, Europe or the rest of the world. PE funds with a US investment focus are used as the reference category. We also measure GP 
location. We make a broad distinction between the location of GPS in the US, Europe or the rest of the world. PE firms located in the US are used as the reference category. The US PE market is generally considered to be the most developed PE market around the globe. We further collected data on PE fund industry focus. We create dummy variables, using predefined Preqin categories, indicating whether or not PE fund managers consider investments in agriculture and chemical materials, business and industrial products/services, consumer products/services and retail, energy and environment, financial services, information and communication technology, life sciences, and other industries. These categories are not mutually exclusive because PE funds can take a generalist approach and target several of these sectors. Finally, the vintage year of a fund is the year in which the first capital is called for investment.

\section{Econometric Approach}

We estimate Linear Probability Models (e.g., Bernard and Jensen, 2004; Ganco et al., 2015) with PE firm fixed effects and heteroskedasticity consistent standard errors, clustered at the PE firm level. These fixed effects models have the attractive feature of controlling for all stable characteristics of PE firms, whether measured or not, which is accomplished by using only within-PE firm variation to estimate the regression coefficients. Thus, the PE firm fixed effects, for instance, will absorb all observable and measured factors that remain stable within PE firms over time (i.e., stage focus, geographical focus, location GP, industry focus and vintage year, described above). Interestingly, they also control for unmeasured factors and/or unobservable factors that remain stable within PE firms over time.

This approach allows us to further control for alternative explanations besides our focus on how performance signals of different strengths influence resource mobilization. For instance, preexisting inter-firm ties with LPs may influence resource mobilization, just like GPs' preexisting ties and human capital (e.g., Hallen, 2008). PE firm-level fixed effects control for 
preexisting LP characteristics even when they are not measured. Indeed, we focus on the ability of a first-time PE fund to raise a follow-on fund and once such a first-time fund is formed (as is the case for all funds in our sample), the identity of the LPs does not change over its lifetime (Sahlman, 1990), i.e., no new LPs are added or existing LPs are removed. Moreover, PE firm fixed effects also control for the characteristics of GPs that established the fund (e.g., GPs' education, previous experience and relationships) because the identity of these GPs does not change over the lifetime of the fund. In addition, hires and/or replacements in the GP team managing first-time PE funds are extremely rare over the funds' lifetime (note, moreover, that $50 \%$ of our PE firms already raise a second fund after 3 years). One of the LPs we interviewed confirmed and further highlighted that it is difficult to draw inferences from new GPs' human capital. While a GP might have been involved in a successful PE fund before, much information asymmetry remains about the role of that specific GP, relative to the other partners, in the success of this previous PE fund. Finally, it is also noteworthy that because all GPs raised a firsttime fund, we reduce the possibility that some lack "basic" human capital or social capital that hampers their follow-on fundraising abilities (e.g., Hallen and Eisenhardt, 2012).

\section{RESULTS}

\section{Descriptive Statistics and Correlations}

In Table 1, we provide details on the time-invariant characteristics of the first-time PE funds in our sample. Roughly $46 \%$ of PE firms raised a follow-on fund during the study period (unreported statistics show the average (median) PE firm does so after 4 (3) years). The mean realized performance of the first-time PE funds at the end of their economic lifetime equals $132 \%$. Unreported statistics show that this number is significantly higher for those first-time PE firms that were able to raise a follow-on fund, relative to those that did not raise a follow-on fund $(151.42 \%$ vs. $110.39 \%, \mathrm{p}=0.041)$. The mean first-time PE fund size is about 333 million dollars. 
The majority of first-time PE funds in our sample are buyout funds and have a geographical investment focus on the US. Over $60 \%$ of GPs in our sample are also located in the US. Firsttime PE funds primarily focus on investments in business and industrial products/services, life sciences, and information and communication technologies. Consistent with our sample selection criteria, the vintage years of the first-time PE funds are between 1999 and 2007.

[Insert Table 1 about here]

In Table 2, we provide descriptive statistics and correlations on the time-varying variables. While $46 \%$ of PE firms raised a follow-on fund during the study period (as shown above), Table 2 shows that raising a follow-on fund is a relatively infrequent event at $7 \%$ of firm-year observations. Bivariate correlations suggest that realized performance and unrealized performance are negatively correlated. Unrealized performance is positively correlated with media attention, but we do not find a significant correlation between realized performance and media attention. Unsurprisingly, PE fund age is positively correlated with realized performance, negatively correlated with unrealized performance, and positively correlated with called capital.

[Insert Table 2 about here]

\section{Signal Strength: Unrealized Performance, Realized Performance, and Eventual Realized Performance}

We have argued that unrealized performance is a weak signal while realized performance is a strong signal, i.e. that realized performance at the end of a fund's economic lifetime (or the unobservable firm quality) is more strongly correlated with realized than with unrealized performance at the time of fundraising.

Table 3 reports evidence on the signal strength of realized and unrealized performance controlling for a range of other variables. In Model 1, using the eventual realized performance at the end of the fund's economic lifetime (i.e., when all funds have been redistributed to the LPs) 
as dependent variable, we find that for any $1 \%$ higher unrealized performance, the expected eventual realized performance will be only approximately $0.14 \%$ higher. ${ }^{11}$ For any $1 \%$ higher realized performance, the expected eventual realized performance will be approximately $0.47 \%$ higher. The coefficient of unrealized performance is also significantly lower than the coefficient of realized performance (at $\mathrm{p}<0.001$ ). In Model 2, using the eventual realized performance at the end of the fund's economic lifetime minus the realized performance already locked-in, we find that for any $1 \%$ higher unrealized performance, the expected eventual realized performance (excluding the realized performance that was already locked-in) will be approximately $0.65 \%$ higher. Finally, in Model 3, we use the same dependent variable as in Model 2 but additionally include PE firm fixed effects. We find that for any $1 \%$ increase in unrealized performance within a first-time PE fund, the expected eventual realized performance (excluding the realized performance that was already locked-in) will be approximately $0.55 \%$ higher. ${ }^{12}$ Note that when realized performance increases within a PE fund this will fully contribute to its eventual realized performance, while for an increase in unrealized performance just over half of the increase will eventually get realized.

Overall, unrealized performance is correlated with eventual realized performance, but only moderately so. In particular, the analyses confirm that unrealized performance is a weaker signal than realized performance.

\section{[Insert Table 3 about here]}

\section{Hypotheses Tests}

\footnotetext{
11 We cannot include a model with PE firm fixed effects because the dependent variable (eventual realized performance) shows no variation within PE firms. Below, we focus on an alternative dependent variable (i.e., eventual realized performance minus the realized performance that is already locked-in). This dependent variable does vary within PE firms and hence we can also report a model including PE firm fixed effects as we do below.

${ }^{12}$ It is also interesting to note that in unreported tests the interaction between unrealized performance and media attention was not statistically significant.
} 
In Table 4, we report the results of our multivariate Linear Probability Models with PE firm fixed effects and with heteroskedasticity consistent standard errors, clustered at the PE firm level. In Model 1, we only include the control variables. In Model 2, we add the independent variables (i.e., unrealized performance and realized performance) and the moderator variable (i.e., media attention). In Model 3, we include the interaction between unrealized performance and media attention. In Model 4, we include the interaction between realized performance and media attention. Model 5 is the full model.

[Insert Table 4 about here]

Hypothesis 1 stated that higher unrealized performance of first-time PE funds would increase the likelihood of raising a follow-on fund. Model 2 shows a positive and statistically significant relationship between the unrealized performance of first-time PE funds $(\beta=0.022 ; \mathrm{p}$ $<0.01)$ and the likelihood of raising a follow-on fund. This result is also confirmed in the other models. In terms of economic significance, these findings suggest that when taking all other values at their mean level, moving from low unrealized performance (mean - 1 S.D.) to high unrealized performance (mean +1 S.D.) increases the probability of raising a follow-on fund from $4.4 \%$ to $10.4 \%$. Overall, we find supporting evidence for Hypothesis 1.

Hypothesis 2 stated that the impact of higher unrealized performance of first-time PE funds on the likelihood of raising a follow-on fund would be weaker than the impact of realized performance on the likelihood of raising a follow-on fund. Model 2 shows a positive and statistically significant relationship between the realized performance of first-time PE funds $(\beta=$ 0.035; $\mathrm{p}<0.01)$ and the likelihood of raising a follow-on fund. This effect is economically significant as well. Taking all other values at their mean level, moving from low realized performance (mean -1 S.D.) to high realized performance (mean +1 S.D.) increases the 
probability of raising a follow-on fund from $0.1 \%$ to $14.1 \%$. A qualitative comparison of the coefficients suggests that the effect of unrealized performance is smaller than the effect of realized performance. However, while qualitative comparisons of the coefficients are instructive, they do not provide statistical evidence for our hypothesis. Using the lincom command in Stata, which allows for testing the difference between coefficients of different variables in the same model (see also Ertug and Castellucci, 2013; Vanacker and Forbes, 2016; Wade et al., 2006), we fail to find a statistically significant difference between both coefficients $(p=0.286)$. Thus, we fail to find statistical support for Hypothesis 2.

Hypothesis 3 stated that media attention would positively moderate the relationship between higher unrealized performance of first-time PE funds and the likelihood of raising a follow-on fund. In Model 3, we find that the interaction term between unrealized performance and media attention is positive and statistically significant $(\beta=0.011 ; \mathrm{p}<0.01)$. Figure 1 graphically illustrates the interaction effect. This figure shows that for PE firms with low media attention (mean - 1 S.D.) and taking all other variables at their mean level, moving from low unrealized performance (mean -1 S.D.) to high unrealized performance (mean +1 S.D.) increases the probability of raising a follow-on fund from $2.1 \%$ to $5.1 \%$, thus increasing the probability of raising a second fund 2.45-fold. However, for PE firms with high media attention (mean +1 S.D.) moving from low unrealized performance (mean -1 S.D.) to high unrealized performance (mean +1 S.D.) increases the probability of raising a follow on fund from $5.4 \%$ to $16.2 \%$, thus increasing the probability of raising a second fund 3 -fold. These effects are clearly also economically significant. Overall, we find supporting evidence for Hypothesis 3.

[Include Figure 1 about here] 
Finally, Hypothesis 4 stated that media attention would more positively moderate the relationship between higher unrealized performance of first-time funds and the likelihood of raising a follow-on fund than the relationship between realized performance and the likelihood of raising a follow-on fund. Consistent with this idea, a visual inspection shows that, in Model 3, the interaction between unrealized performance and media attention is positive and significant ( $\beta$ $=0.011 ; \mathrm{p}<0.01)$, while in Model 4 the interaction between realized performance and media attention is negative and not statistically significant $(\beta=-0.005 ; \mathrm{p}>0.10)$. These findings are also consistent with those in Model 5, the full model. Using the lincom command in Stata, we examine whether in Model 5 the interaction term between unrealized performance and media attention is also statistically different from the interaction term between realized performance and media attention. The test is highly significant $(\mathrm{p}=0.005)$, thereby providing evidence that the moderating effect of media attention is stronger for the relationship between unrealized performance and the likelihood of raising a follow-on fund than for the relationship between realized performance and the likelihood of raising a follow-on fund. Overall, we find supporting evidence for Hypothesis 4.

\section{Robustness Tests}

We performed additional tests to examine the robustness of our findings. These tests are described below (detailed results are not reported but available upon request).

First, we used alternative media attention measures. In our sample, all PE firms manage their first-time fund; consequently, "firm" and "fund" can be used largely interchangeably. However, in some cases, the name of the PE firm is different from the name of its fund. In our primary analysis, our media attention measure was calculated as the natural logarithm of the number of media citations to the PE firm (plus 1) in $t-1$. We also used equivalent measures that count (a) the number of media citations to the PE fund and (b) both media citations to the PE 
firm and PE fund. These measures are positively correlated (all above 0.60). Our multivariate results also remain robust using these alternative measures and provide similar evaluations of our Hypotheses 3 and 4 .

Second, we used an alternative econometric approach, namely a complementary log-log random effects model (with robust standard errors, clustered at the PE firm level) to account for the fact that our dependent variable is a rare event at any point in time (Coff, 2003). The complementary log-log model has the advantage of providing close similarity to continuous time models, such as the Cox regression model (Allison, 1995). The former approach, however, which is invariant to interval length, is more suitable relative to continuous time models because we do not have continuous data but rather rely on yearly data (Allison, 1995). Our multivariate results also remain robust using this alternative econometric approach. Specifically, we find supporting evidence for Hypotheses 1, 3 and 4 but fail to find evidence for Hypothesis 2.

Third, we reran our analysis using a subsample of 125 GPs that are located in the US, to ensure homogeneity in the institutional environment. Consistent with our previous findings related to Hypothesis 1, unrealized performance has a positive effect on the probability of raising a follow-on fund, although this effect is statistically insignificant. In this US sample, we do find evidence consistent with Hypothesis 2, that is, the effect of unrealized performance is weaker than the effect of realized performance. In addition, we find strong support for Hypothesis 3 and Hypothesis 4. Thus, insights from tests on a subsample of US-based GPs are qualitatively similar to the results in our main tests using a global dataset. Moreover, when in additional tests, we further focused on a related subsample of first-time PE funds with a geographical investment focus on the US, we again found virtually similar results. 
Fourth, one may argue that media attention is endogenously determined and that timevarying unobservable characteristics influence both media attention and the unobservable fundraising abilities of PE managers. (Note that time-invariant unobservable factors are accounted for in our primary analysis using PE firm fixed effects). In other words, the "best" PE firms may attract the most media attention, thereby causing a spurious correlation between media attention and the ability to raise a second fund. However, if this were true one would expect media attention to correlate with realized performance as well, whereas our correlation matrix (Table 2) suggests that media attention is weakly correlated with unrealized performance but not with realized performance. Moreover, Table 3 shows that PE firms that attract more media attention do not exhibit higher eventual realized performance (at the end of the funds' lifetime). In fact, Model 3 with PE firm fixed effects shows that additional media attention is related to lower eventual realized performance. Thus, these findings suggest no correlation (or a negative correlation) between media attention and eventual realized performance, which makes endogenous explanations related to our Hypothesis 3 and Hypothesis 4 unlikely. Moreover, our primary interest is not in the main effect of media attention but in its interaction with unrealized and realized performance, respectively. For interaction terms, standard econometric approaches are "often at least as credible as instrumental variable (IV) inference" particularly in the commonplace case where the validity of IVs is questionable (Bun and Harrison, 2014: 2-3). Finally, to account for the concern that interaction terms in fixed effects models may no longer reflect within-firm effects, we estimated a "double-demeaned" estimator of the interaction between unrealized performance and media attention (Giesselmann and Schmidt-Catran, 2018). Our results remained robust (i.e., the coefficient remained positive and significant). 


\section{DISCUSSION AND CONCLUSION}

It is well-established that new firms can attract resources more readily when they communicate signals that credibly convey their unobservable quality. However, we know little about how multiple simultaneous signals of different strengths influence resource provision decisions. Indeed, much of the signaling literature has focused on signals that are (implicitly) assumed to be strong. Moreover, this literature has often assumed that prospective resource providers attend to and evaluate these signals in a social vacuum, independently of the social context. In this paper, we addressed these common assumptions in the signaling literature. We drew on a sociocognitive perspective to develop hypotheses concerning the effectiveness of weak versus strong signals and the role of the media, an important information intermediary in a firm's social context, on the effectiveness of such distinct signals. We empirically tested our hypotheses using unique longitudinal data on the fundraising activities of 205 first-time PE funds. Our research context is one where informational asymmetry problems and uncertainty are especially acute and where the inability of PE managers to raise a second fund entails that they will ultimately be forced to exit the PE business.

Our findings are broadly in line with our hypotheses. Consistent with Hypothesis 1, we find that first-time PE funds with higher unrealized performance, a relatively weak signal, are more likely to raise a follow-on fund. While we find that the economic impact of unrealized performance is weaker than that of realized performance, we fail to find statistical evidence (in the full sample) that the effectiveness of unrealized performance is weaker than the effectiveness of realized performance, i.e. the stronger signal. Thus, we find no statistical support for Hypothesis 2. Consistent with Hypothesis 3, we find evidence that the relationship between unrealized performance and fundraising is much stronger for PE firms that attract significant media attention. Moreover, consistent with Hypothesis 4, the effectiveness of realized 
performance for fundraising is less affected by the media attention PE firms attract than that of unrealized performance.

The lack of statistical support for Hypothesis 2 in the full sample, which focuses on the average effectiveness of strong versus weak signals, can be explained by the results related to our moderation Hypothesis 3. This hypothesis argues that the effectiveness of weak signals depends on the media attention firms receive. Our findings confirm that for new PE firms with limited media attention, the effect of unrealized performance is statistically much weaker than the effect of realized performance. Moreover, it is worth noting that we find both economically and statistically significant effects that support Hypothesis 2 in the subsample of US-based PE funds. Overall, these findings suggest that the limited support for Hypothesis 2 may be due to contextual factors that make average comparisons (in samples with PE firms that attract fundamentally different levels of attention from the media and samples in which there is important geographical diversity) between unrealized and realized performance challenging. However, our strong evidence for Hypothesis 3 and 4 suggests that a differentiation between signals of varying strength remains important to understand the effectiveness of these distinct signals.

\section{Contributions to Theory}

Our findings contribute to the signaling literature in several ways. First, past studies of signaling have generally not accounted for the possibility that distinct signals may differ in strength. If anything, it is often (implicitly) assumed that the signals under investigation are strong signals (i.e., that they are significantly correlated with unobservable quality), although this assumption is rarely tested. Indeed, after an extensive review of the signaling literature, Bergh and colleagues (2014: 1347) observed that none of the studies in their review "empirically incorporated signal confirmation" thereby leaving many potential research avenues under-explored. In our context, 
signal confirmation would entail that the signals are shown to be (differently) correlated with the new PE firm's ability to generate returns. We investigate two distinct performance signals (e.g., Fombrun and Shanley, 1990), where we argue that realized performance is a stronger signal, while unrealized performance is a weaker signal. We also provide empirical evidence for the difference in signal strength by showing that realized performance has a stronger correlation with the eventual return realized at the end of a fund's lifetime relative to unrealized performance.

Having established that our two performance signals differ significantly in strength, this forms the basis for a set of broader contributions that advance a sociocognitive view on signaling. First, traditional signaling theory has usually focused on how a specific signal may create a separating equilibrium between high-quality and low-quality firms (e.g., Spence, 1973). However, in the management domain, it is well established that firms often convey multiple signals simultaneously. Signaling theory, however, remains rather silent on how resource providers may attend to and evaluate multiple signals (e.g., Drover et al., 2018), especially when these signals are of different strengths and thus create a situation where they could be "rank ordered". Our study is important because it shows that weak signals can also influence resource provision decisions and provides an explanation of why such signals matter, even when controlling for the availability of strong signals.

Second, prospective resource providers are often assumed to attend to and evaluate signals conveyed by firms in a social vacuum. Sensing this limitation, Connelly and colleagues (2011: 62) observed that the "signaling environment is on the whole an underresearched aspect of signaling theory". Our study shows that the effects of weak signals, in particular, are significantly influenced by firms' media attention. By doing so, our study contributes to an increasing body of literature that shows that the value of signaling is contingent upon various 
factors, including basic firm characteristics (Stuart et al., 1999), the availability of other signals (Ozmel et al., 2013; Plummer et al., 2016), market conditions (Gulati and Higgins, 2003) and time (Pollock and Gulati, 2007). More specifically, we point to a new dimension of the contingent value of signaling, namely a firm's media attention, which determines the effectiveness of weak signals.

Our findings are in line with other influential work taking a sociocognitive perspective that has focused on how the media affects attention allocation towards firms and affects the evaluation of firms, thereby influencing resource provision decisions (Petkova et al., 2013; Pollock and Rindova, 2003; Pollock et al., 2008). Studies in this domain, however, have often focused on the media's legitimization role, irrespective of the signals firms convey. In our study, we have demonstrated that, while media attention indeed has a direct effect on firms, the effectiveness of signaling and media attention are also interrelated. Our study provides the basis for a theoretical integration of signaling literature with work on the role of information intermediaries, two streams of research that have remained largely unconnected (e.g., Pollock and Rindova, 2003).

\section{Limitations and Avenues for Future Research}

Our findings suggest that scholars could draw further on a sociocognitive perspective to better understand how and when resource provisions decisions are more or less influenced by different signals (e.g., Connelly et al., 2011). First, future research could examine the generalizability of our findings on the effectiveness of weak signals and the effect of media attention on their effectiveness in other contexts than the PE context. To do so, scholars are aided by the fact that firms in other entrepreneurial settings also often communicate their generally limited track record of past realized performance (e.g., Hallen, 2008) and their prospects for future performance, i.e. unrealized performance (e.g., Kirsch et al., 2009). 
Second, given our focus on unrealized performance, ample opportunities also exist to examine other types of weak signals, for example, announcements about future actions. Future research could also draw on a cognitive perspective to unravel whether different sets of prospective resource providers attend differently to signals of different strengths (e.g., capital providers versus employees). While the resource mobilization and signaling literature streams have largely focused on the mobilization of financial resources (Clough et al., 2019), firms need to mobilize other types of resources as well, and different types of resource providers may differently attend to and evaluate different types of signals (e.g., Vanacker and Forbes, 2016). In our study, we focused on capital providers to PE funds, which are generally sophisticated players with significant financial experience. If weak signals influence such sophisticated investors, one could expect the effects to be even stronger for less sophisticated resource providers. However, all these issues remain subject to future research.

Third, while the distinction between "attention" and "evaluation" is well recognized in sociocognitive studies (Fiske and Taylor 1991), it is empirically challenging to separate both phases in decision making. Indeed, management research has often theorized on both phases but, just like in our study, researchers often do not separately examine prospective resource providers consideration set and their evaluation process. Rather, empirical research including ours often focuses directly on the outcome, that is, the resource provision decision. This limitation opens up important avenues for future research. Particularly, management scholars could pay more specific attention to these intermediary phases. In doing so, the marketing literature on consideration set formation (e.g., Hauser, 2014) might be particularly valuable to further increase our understanding of how firms can enter into the consideration set of prospective resource providers. 
Finally, an implicit assumption in our study is that new PE firms want to raise a followon fund. This assumption is commonplace because PE managers need to raise a follow-on fund to remain in business. However, there is a possibility that exceptional situations such as partner conflicts or departures may push firms to decide not to raise a follow-on fund. An important avenue for future research is to investigate how such factors may influence the decision to raise a follow-on fund.

\section{Practical Implications}

Our study also has implications for practice. Firms should appreciate the potential consequences of signals of different strengths, and particularly weak signals, for resource mobilization.

Firms are generally advised to convey strong signals to resource providers in order to facilitate resource mobilization. These strong signals could include affiliations with prominent affiliates. However, this advice often confronts firms with a "chicken-and-egg" conundrum. How can firms attract prominent affiliates in the first place, when these prominent affiliates also rely on strong signals when making their affiliation decisions? Our findings suggest that in certain cases, firms may be able to draw the attention of prospective resource providers to their firms and be evaluated positively through conveying relatively weak signals. Such weak signals may be more readily available to new firms with high-quality prospects than strong signals.

The possibility that weak signals also foster resource mobilization may be a particularly attractive feature when firms have significant potential that is not yet realized. Indeed, in an attempt to show realized performance (a strong signal) early-on, firms may leave money on the table (e.g., Gompers, 1996). Rather, firms can also convey weaker signals such as their unrealized performance or performance potential. When effective, this may allow firms to reduce their costs related to signaling, to a situation where firms can enter into the consideration set of 
prospective resource providers and let the latter bear the cost of due diligence to examine the credibility of those weak signals in more detail.

However, our findings also show that the effect of weak signals is not "automatic". Specifically, weak signals become much more effective when firms have attracted the attention of the media. While some of this media attention might be out of the control of new firms, they can also proactively influence the media attention they attract to some degree, for example by speaking at industry events or engaging in customer education efforts (Petkova, 2012; Petkova et al., 2013). Moreover, in our analysis of media reports, we noticed that some of these relate to simple expositions on the state of the industry the firm is in. While these media reports might be viewed as trivial, our results suggest that they can have profound effects on firms' subsequent search for key resources.

\section{Concluding Note}

In closing, drawing on a sociocognitive perspective, we have investigated the effectiveness of signals of different strengths for new firm resource mobilization and how their effectiveness depends on the attention new firms attracted from the media, an important information intermediary in a firm's social context. We hope this study encourages additional research examining the effects of different types of signals and their contingent value for new firms interacting with different groups of prospective resource providers in a socially-rich environment.

\section{REFERENCES}

Akerlof, G. A. (1970). The market for "lemons": Quality uncertainty and the market mechanism. Quarterly Journal of Economics, 84(3), 488-500. Aldrich, H., \& Ruef, M. (2006). Organizations evolving, 2nd ed. (Sage, London). Allison, P. D. (1995). Survival analysis using SAS: A practical guide. SAS Institute. Inc., Cary, NC.

Ariely, D., Loewenstein, G., \& Prelec, D. (2003). "Coherent arbitrariness": Stable demand curves without stable preferences. Quarterly Journal of Economics, 118(1), 73-106. 
Balboa, M., \& Martí, J. (2007). Factors that determine the reputation of private equity managers in developing markets. Journal of Business Venturing, 22(4), 453-480.

Barber, B. M., \& Yasuda, A. (2017). Interim fund performance and fundraising in private equity. Journal of Financial Economics, 124(1), 172-194.

Baum, J. A., \& Silverman, B. S. (2004). Picking winners or building them? Alliance, intellectual, and human capital as selection criteria in venture financing and performance of biotechnology startups. Journal of Business Venturing, 19(3), 411-436.

Bednar, M. K. (2012). Watchdog or lapdog? A behavioral view of the media as a corporate governance mechanism. Academy of Management Journal, 55(1), 131-150.

Bednar, M. K., Boivie, S., \& Prince, N. R. (2013). Burr under the saddle: How media coverage influences strategic change. Organization Science, 24(3), 910-925.

Bergh, D. D., Connelly, B. L., Ketchen, D. J., \& Shannon, L. M. (2014). Signalling theory and equilibrium in strategic management research: An assessment and a research agenda. Journal of Management Studies, 51(8), 1334-1360.

Bernard, A. B., \& Jensen, J. B. (2004). Why some firms export. Review of Economics and Statistics, 86(2), 561-569.

Bitektine, A. (2011). Toward a theory of social judgments of organizations: The case of legitimacy, reputation, and status. Academy of Management Review, 36(1), 151-179.

Boivin, J., Chan, P., Paul, V., \& Wittlin, J. (2019). The core role of private markets in modern portfolios. Blackrock investment institute. Accessible at: https:/www.blackrock.com/institutions/en-gb/literature/whitepaper/bii-portfolio-constructionprivate-markets-march-2019.pdf.

Bromiley, P. (1991). Testing a causal model of corporate risk taking and performance. Academy of Management Journal, 34(1), 37-59.

Bun, M. J., \& Harrison, T. D. (2014) OLS and IV estimation of regression models including endogenous interaction terms. University of Amsterdam. Accessible at: https://ideas.repec.org/p/ame/wpaper/1402.html.

Certo, S. T. (2003). Influencing initial public offering investors with prestige: Signaling with board structures. Academy of Management Review, 28(3), 432-446.

Clough, D. R., Fang, T. P., Vissa, B., \& Wu, A. (2019). Turning lead into gold: How do entrepreneurs mobilize resources to exploit opportunities? Academy of Management Annals, 13(1), 240-271.

Coff, R. (2003). Bidding wars over R\&D-intensive firms: Knowledge, opportunism, and the market for corporate control. Academy of Management Journal, 46(1), 74-85.

Connelly, B. L., Certo, S. T., Ireland, R. D., \& Reutzel, C. R. (2011). Signaling theory: A review and assessment. Journal of Management, 37(1), 39-67.

Cumming, D., Fleming, G., \& Suchard, J. A. (2005). Venture capitalist value-added activities, fundraising and drawdowns. Journal of Banking \& Finance, 29(2), 295-331.

Cumming, D., \& Walz, U. (2010). Private equity returns and disclosure around the world. Journal of International Business Studies, 41(4), 727-754.

Damodaran, A. (2006). Damodaran on valuation: Security analysis for investment and corporate finance. Wiley (2nd Edition).

Dimov, D., Shepherd, D. A., \& Sutcliffe, K. M. (2007). Requisite expertise, firm reputation, and status in venture capital investment allocation decisions. Journal of Business Venturing, 22(4), 481-502. 
Dimov, D., \& Gedajlovic, E. (2010). A property rights perspective on venture capital investment decisions. Journal of Management Studies, 47(7), 1248-1271.

Drover, W., Wood, M. S., \& Corbett, A. C. (2018). Toward a cognitive view of signalling theory: individual attention and signal set interpretation. Journal of Management Studies, 55(2), 209-231.

Ertug, G., \& Castellucci, F. (2013). Getting what you need: How reputation and status affect team performance, hiring, and salaries in the NBA. Academy of Management Journal, 56(2), 407-431.

Felin, T., Koenderink, J., \& Krueger, J. I. (2017). Rationality, perception, and the all-seeing eye. Psychonomic Bulletin \& Review, 24(4), 1040-1059.

Fiske, S. T., \& Taylor, S. E. (1991). Social cognition. McGraw-Hill Book Company.

Fombrun, C., \& Shanley, M. (1990). What's in a name? Reputation building and corporate strategy. Academy of Management Journal, 33(2), 233-258.

Freeman, J. (2005). Venture capital and modern capitalism. Princeton Univ. Press.

Ganco, M., Ziedonis, R. H., \& Agarwal, R. (2015). More stars stay, but the brightest ones still leave: Job hopping in the shadow of patent enforcement. Strategic Management Journal, 36(5), 659-685.

Gavetti, G., Levinthal, D., \& Ocasio, W. (2007). Perspective-Neo-Carnegie: The Carnegie school's past, present, and reconstructing for the future. Organization Science, 18(3), 523536.

Gemser, G., Leenders, M. A., \& Wijnberg, N. M. (2008). Why some awards are more effective signals of quality than others: A study of movie awards. Journal of Management, 34(1), 2554.

Giesselmann, M., \& Schmidt-Catran, A. (2018). Interactions in fixed effects regression models. DIW Berlin Discussion Paper No. 1748. Accessible at: https://ssrn.com/abstract $=3227779$

Gompers, P. A. (1996). Grandstanding in the venture capital industry. Journal of Financial Economics, 42(1), 133-156.

Gompers, P. A., \& Lerner, J. (1998). What drives venture capital fundraising? Brookings Papers on Economic Activity. Microeconomics, 149-204.

Gulati, R., \& Higgins, M. C. (2003). Which ties matter when? The contingent effects of interorganizational partnerships on IPO success. Strategic Management Journal, 24(2), 127 144.

Hallen, B. L. (2008). The causes and consequences of the initial network positions of new organizations: From whom do entrepreneurs receive investments? Administrative Science Quarterly, 53(4), 685-718.

Hallen, B. L., \& Eisenhardt, K. M. (2012). Catalyzing strategies and efficient tie formation: How entrepreneurial firms obtain investment ties. Academy of Management Journal, 55(1), 35-70.

Hallen, B. L., \& Pahnke, E. C. (2016). When do entrepreneurs accurately evaluate venture capital firms' track records? A bounded rationality perspective. Academy of Management Journal, 59(5), 1535-1560.

Harris, R. S., Jenkinson, T., \& Kaplan, S. N. (2014). Private equity performance: What do we know? Journal of Finance, 69(5), 1851-1882.

Harrison, A. A. (1977). Mere exposure. Advances in Experimental Social Psychology, 10, 3983.

Hauser, J. R. (2014). Consideration-set heuristics. Journal of Business Research, 67(8), 16881699. 
Higgins, M. C., \& Gulati, R. (2006). Stacking the deck: The effects of top management backgrounds on investor decisions. Strategic Management Journal, 27(1), 1-25.

Hoffman, A. J., \& Ocasio, W. (2001). Not all events are attended equally: Toward a middlerange theory of industry attention to external events. Organization Science, 12(4), 414-434.

Jenkinson, T., Sousa, M., \& Stucke, R. (2013). How fair are the valuations of private equity funds? University of Oxford, working paper. Accessible at: https://ssrn.com/abstract $=2229547$.

Jensen, M., \& Roy, A. (2008). Staging exchange partner choices: When do status and reputation matter? Academy of Management Journal, 51(3), 495-516.

Jensen, M., Kim, H., \& Kim, B. K. (2012). Meeting expectations: A roletheoretic perspective on reputation. In Barnett M. L., \& Pollock, T.G. (Eds.), The Oxford Handbook of Corporate Reputation (Oxford University Press, Oxford, UK), 140-159.

Kaplan, S. N., \& Lerner, J. (2016). Venture capital data: Opportunities and challenges (No. w22500). National Bureau of Economic Research.

Kerr, W. R., Nanda, R., \& Rhodes-Kropf, M. (2014). Entrepreneurship as experimentation. Journal of Economic Perspectives, 28(3), 25-48.

Kim, H., \& Jensen, M. (2014). Audience heterogeneity and the effectiveness of market signals: How to overcome liabilities of foreignness in film exports? Academy of Management Journal, 57(5), 1360-1384.

Kirsch, D., Goldfarb, B., \& Gera, A. (2009). Form or substance: The role of business plans in venture capital decision making. Strategic Management Journal, 30(5), 487-515.

Kutner, M., Nachtsheim, C., Neter, J. and Li, W. (2005). Applied linear statistical models. 5th ed. Boston: McGraw-Hill.

Lee, P. M. (2001). What's in a name. com?: The effects of '. com' name changes on stock prices and trading activity. Strategic Management Journal, 22(8), 793-804.

Liu, L. X., Sherman, A. E., \& Zhang, Y. (2014). The long-run role of the media: Evidence from initial public offerings. Management Science, 60(8), 1945-1964.

Martens, M. L., Jennings, J. E., \& Jennings, P. D. (2007). Do the stories they tell get them the money they need? The role of entrepreneurial narratives in resource acquisition. Academy of Management Journal, 50(5), 1107-1132.

McDonnell, M. H., \& King, B. (2013). Keeping up appearances: Reputational threat and impression management after social movement boycotts. Administrative Science Quarterly, 58(3), 387-419.

Merton, R. C. (1987). A simple model of capital market equilibrium with incomplete information. Journal of Finance, 42(3), 483-510.

Northcraft, G. B., \& Neale, M. A. (1987). Experts, amateurs, and real estate: An anchoring-andadjustment perspective on property pricing decisions. Organizational Behavior and Human Decision Processes, 39(1), 84-97.

Ozmel, U., Reuer, J. J., \& Gulati, R. (2013). Signals across multiple networks: How venture capital and alliance networks affect interorganizational collaboration. Academy of Management Journal, 56(3), 852-866.

Park, N. K., \& Mezias, J. M. (2005). Before and after the technology sector crash: The effect of environmental munificence on stock market response to alliances of e-commerce firms. Strategic Management Journal, 26(11), 987-1007. 
Petkova A. P. (2012). From the ground up: Building young firms' reputations. In Barnett M. L., \& Pollock, T.G. (Eds.), The Oxford Handbook of Corporate Reputation (Oxford University Press, Oxford, UK), 383-401.

Petkova, A. P., Rindova, V. P., \& Gupta, A. K. (2013). No news is bad news: Sensegiving activities, media attention, and venture capital funding of new technology organizations. Organization Science, 24(3), 865-888.

Plummer, L. A., Allison, T. H., \& Connelly, B. L. (2016). Better together? Signaling interactions in new venture pursuit of initial external capital. Academy of Management Journal, 59(5), 1585-1604.

Pollock, T. G., \& Rindova, V. P. (2003). Media legitimation effects in the market for initial public offerings. Academy of Management Journal, 46(5), 631-642.

Pollock, T. G., \& Gulati, R. (2007). Standing out from the crowd: The visibility-enhancing effects of IPO-related signals on alliance formation by entrepreneurial firms. Strategic Organization, 5(4), 339-372.

Pollock, T. G., Rindova, V. P., \& Maggitti, P. G. (2008). Market watch: Information and availability cascades among the media and investors in the US IPO market. Academy of Management Journal, 51(2), 335-358.

Preqin (2014). Key due diligence considerations for private equity investors. Accessible at: https://docs.preqin.com/reports/Preqin-Special-Report-Due-Diligence-Private-EquityInvestors-Jul-14.pdf

Reuer, J. J., Tong, T. W., \& Wu, C. W. (2012). A signaling theory of acquisition premiums: Evidence from IPO targets. Academy of Management Journal, 55(3), 667-683.

Rider, C. I., \& Swaminathan, A. (2011). They just fade away: mortality in the US venture capital industry. Industrial and Corporate Change, 21(1), 151-185.

Rindova, V. P., Reger, R. K., \& Dalpiaz, E. (2012). The mind of the strategist and the eye of the beholder: The socio-cognitive perspective in strategy research. In Handbook of Research on Competitive Strategy. Edward Elgar Publishing Ltd.

Sahlman, W. A. (1990). The structure and governance of venture-capital organizations. Journal of Financial Economics, 27(2), 473-521.

Sammut S. (2011). Venture capital and entrepreneurial management. The University of Pennsylvania, The Wharton School.

Sanders, W. G., \& Boivie, S. (2004). Sorting things out: Valuation of new firms in uncertain markets. Strategic Management Journal, 25(2), 167-186.

Shaver, M. (2007). Interpreting empirical results in strategy and management research. In Ketchen D., Bergh, D. (ed.) Research methodology in strategy and management, Volume 4 Emerald, 273 - 293.

Shroff, N., Verdi, R. S., \& Yu, G. (2013). Information environment and the investment decisions of multinational corporations. The Accounting Review, 89(2), 759-790.

Souitaris, V., Zerbinati, S., Peng, B. G., \& Shepherd, D. A. (2019). Should I stay or should I go? founder power and exit via initial public offering. Academy of Management Journal, In Press, https://doi.org/10.5465/amj.2017.0420.

Spence, M. (1973). Job market signaling. Quarterly Journal of Economics, 87, 355-374.

Spence, M. (2002). Signaling in retrospect and the informational structure of markets. American Economic Review, 92(3), 434-459.

Steigenberger, N., \& Wilhelm, H. (2018). Extending Signaling theory to rhetorical signals: Evidence from crowdfunding. Organization Science, 29(3), 529-546. 
Stern, I., Dukerich, J. M., \& Zajac, E. (2014). Unmixed signals: How reputation and status affect alliance formation. Strategic Management Journal, 35(4), 512-531.

Stinchcombe, A. (1965). Social structure and organizations. In The handbook of organizations. Chicago, IL: Rand McNally.

Strack, F., \& Mussweiler, T. (1997). Explaining the enigmatic anchoring effect: Mechanisms of selective accessibility. Journal of Personality and Social Psychology, 73(3), 437.

Stuart, T. E., Hoang, H., \& Hybels, R. C. (1999). Interorganizational endorsements and the performance of entrepreneurial ventures. Administrative Science Quarterly, 44(2), 315-349.

Thorsteinson, T. J., Breier, J., Atwell, A., Hamilton, C., \& Privette, M. (2008). Anchoring effects on performance judgments. Organizational Behavior and Human Decision Processes, 107(1), 29-40.

Vanacker, T., \& Forbes, D. P. (2016). Disentangling the multiple effects of affiliate reputation on resource attraction in new firms. Organization Science, 27(6), 1525-1547.

Van Exel, N. J. A., Brouwer, W. B., van den Berg, B., \& Koopmanschap, M. A. (2006). With a little help from an anchor: discussion and evidence of anchoring effects in contingent valuation. Journal of Socio-Economics, 35(5), 836-853.

Wade, J. B., O'Reilly III, C. A., \& Pollock, T. G. (2006). Overpaid CEOs and underpaid managers: Fairness and executive compensation. Organization Science, 17(5), 527-544.

Wiklund, J., Wright, M., \& Zahra, S. A. (2019). Conquering relevance: Entrepreneurship research's grand challenge. Entrepreneurship: Theory and Practice, 43(3), 419-436.

Williamson, I. O. (2000). Employer legitimacy and recruitment success in small businesses. Entrepreneurship: Theory and Practice, 25(1), 27-27.

Wiltbank, R. (2005). Investment practices and outcomes of informal venture investors. Venture Capital, 7(4), 343-357.

Wright, M., \& Robbie, K. (1998). Venture capital and private equity: A review and synthesis. Journal of Business Finance \& Accounting, 25(5-6), 521-570.

Zacharakis, A. L., \& Shepherd, D. A. (2001). The nature of information and overconfidence on venture capitalists' decision making. Journal of Business Venturing, 16(4), 311-332.

Zajonc, R. B. (1968). Attitudinal effects of mere exposure. Journal of Personality and Social Psychology, 9(2), 1-27.

Zarutskie, R. (2010). The role of top management team human capital in venture capital markets: Evidence from first-time funds. Journal of Business Venturing, 25(1), 155-172.

Zuckerman, E. W. (1999). The categorical imperative: Securities analysts and the illegitimacy discount. American Journal of Sociology, 104(5), 1398-1438. 
TABLE 1 Characteristics of the 205 New PE Funds

\begin{tabular}{|c|c|c|c|}
\hline & Obs. & Mean & S.D. \\
\hline Raising a follow-on fund & 205 & 0.46 & - \\
\hline Eventual realized performance ${ }^{a}$ & 133 & 132.29 & 140.26 \\
\hline Fund size & 205 & 333.07 & 481.56 \\
\hline \multicolumn{4}{|l|}{ Stage focus } \\
\hline Venture capital & 205 & 0.42 & - \\
\hline Buyout & 205 & 0.58 & - \\
\hline \multicolumn{4}{|l|}{ Geographical focus } \\
\hline US & 205 & 0.63 & - \\
\hline Europe & 205 & 0.25 & - \\
\hline Rest of world & 205 & 0.12 & - \\
\hline \multicolumn{4}{|l|}{ Location GP } \\
\hline US & 205 & 0.61 & - \\
\hline Europe & 205 & 0.23 & - \\
\hline Rest of world & 205 & 0.16 & - \\
\hline \multicolumn{4}{|l|}{ Industry focus } \\
\hline Agriculture and chemical materials & 205 & 0.02 & - \\
\hline Business and industrial products/services & 205 & 0.46 & - \\
\hline Consumer products/services and retail & 205 & 0.24 & - \\
\hline Energy and environment & 205 & 0.15 & - \\
\hline Financial services & 205 & 0.15 & - \\
\hline Information and communication tech & 205 & 0.35 & - \\
\hline Life sciences & 205 & 0.39 & - \\
\hline Other industries & 205 & 0.22 & - \\
\hline \multicolumn{4}{|l|}{ Vintage year } \\
\hline 1999 & 205 & 0.06 & - \\
\hline 2000 & 205 & 0.12 & - \\
\hline 2001 & 205 & 0.11 & - \\
\hline 2002 & 205 & 0.07 & - \\
\hline 2003 & 205 & 0.07 & - \\
\hline 2004 & 205 & 0.14 & - \\
\hline 2005 & 205 & 0.08 & - \\
\hline 2006 & 205 & 0.11 & - \\
\hline 2007 & 205 & 0.16 & - \\
\hline
\end{tabular}

a The descriptive statistics of the untransformed variable are reported here. The natural logarithm of eventual realized performance is used in Table 3. 


\section{TABLE 2 Descriptive Statistics and Correlations}

\begin{tabular}{|c|c|c|c|c|c|c|c|c|c|c|c|}
\hline & & Obs. & Mean & S.D. & 1 & 2 & 3 & 4 & 5 & 6 & 7 \\
\hline 1 & Raising a follow-on fund & 1,057 & 0.07 & - & 1.00 & & & & & & \\
\hline 2 & Unrealized performance ${ }^{a}$ & 1,057 & 74.26 & 88.14 & 0.15 & 1.00 & & & & & \\
\hline 3 & Realized performance ${ }^{a}$ & 1,057 & 49.04 & 108.45 & 0.02 & -0.40 & 1.00 & & & & \\
\hline 4 & Media attention $^{\mathrm{a}}$ & 1,057 & 9.55 & 26.63 & 0.05 & 0.11 & -0.05 & 1.00 & & & \\
\hline 5 & Fund age & 1,057 & 5.38 & 3.73 & -0.13 & -0.59 & 0.66 & -0.09 & 1.00 & & \\
\hline 6 & Called capital & 1,057 & 0.75 & 0.81 & -0.01 & 0.00 & 0.35 & -0.02 & 0.21 & 1.00 & \\
\hline 7 & S\&P500 return & 1,057 & 8.04 & 17.78 & -0.01 & -0.11 & 0.15 & -0.07 & 0.26 & 0.04 & 1.00 \\
\hline 8 & PE on GDP & 1,057 & 0.87 & 0.41 & 0.08 & 0.11 & -0.04 & 0.06 & -0.18 & 0.02 & -0.33 \\
\hline
\end{tabular}

Notes. Correlations in bold are significant at $\mathrm{p}<0.05$.

a The descriptive statistics of the untransformed variables are reported here. The natural logarithm of the variables are used for the correlations and multivariate regressions reported below. 
TABLE 3 Unrealized Performance and Realized Performance as Determinants of Eventual Realized Performance

\begin{tabular}{|c|c|c|c|}
\hline & \multirow{2}{*}{$\begin{array}{c}\text { DV: Eventual } \\
\text { realized performance } \\
\text { M1 }\end{array}$} & \multicolumn{2}{|c|}{$\begin{array}{l}\text { DV: Eventual realized performance minus } \\
\text { realized performance already locked-in }\end{array}$} \\
\hline & & M2 & M3 \\
\hline Unrealized performance & $\begin{array}{c}0.136^{* *} \\
{[0.064]}\end{array}$ & $\begin{array}{c}0.650 * * * \\
{[0.083]}\end{array}$ & $\begin{array}{c}0.548 * * * \\
{[0.092]}\end{array}$ \\
\hline Realized performance & $\begin{array}{c}0.468 * * * \\
{[0.068]}\end{array}$ & - & - \\
\hline Media attention & $\begin{array}{l}-0.003 \\
{[0.045]}\end{array}$ & $\begin{array}{c}-0.074 \\
{[0.062]}\end{array}$ & $\begin{array}{c}-0.125 * * * \\
{[0.039]}\end{array}$ \\
\hline Venture capital & $\begin{array}{l}-0.405^{*} \\
{[0.213]}\end{array}$ & $\begin{array}{l}-0.661 * * * \\
{[0.249]}\end{array}$ & - \\
\hline Ln fund size & $\begin{array}{c}0.112 \\
{[0.078]}\end{array}$ & $\begin{array}{c}0.150 \\
{[0.107]}\end{array}$ & - \\
\hline Fund age & $\begin{array}{c}-0.215 * * \\
{[0.091]}\end{array}$ & $\begin{array}{l}-0.070 \\
{[0.118]}\end{array}$ & $\begin{array}{c}-0.323 * * * \\
{[0.067]}\end{array}$ \\
\hline Fund age squared & $\begin{array}{l}0.010^{* *} \\
{[0.004]}\end{array}$ & $\begin{array}{l}-0.001 \\
{[0.006]}\end{array}$ & $\begin{array}{c}0.006 \\
{[0.005]}\end{array}$ \\
\hline Called capital & $\begin{array}{l}-0.182 \\
{[0.399]}\end{array}$ & $\begin{array}{c}0.225 \\
{[0.477]}\end{array}$ & $\begin{array}{c}1.002 * * * \\
{[0.346]}\end{array}$ \\
\hline $\begin{array}{l}\text { Geographical rest of } \\
\text { world }\end{array}$ & $\begin{array}{c}0.343 \\
{[0.617]}\end{array}$ & $\begin{array}{c}0.485 \\
{[0.938]}\end{array}$ & - \\
\hline Geographical Europe & $\begin{array}{c}0.303 \\
{[0.388]}\end{array}$ & $\begin{array}{c}-0.004 \\
{[0.602]}\end{array}$ & - \\
\hline Location GP rest of world & $\begin{array}{l}-0.057 \\
{[0.588]}\end{array}$ & $\begin{array}{l}-0.471 \\
{[0.910]}\end{array}$ & - \\
\hline Location GP Europe & $\begin{array}{l}-0.123 \\
{[0.388]}\end{array}$ & $\begin{array}{l}-0.027 \\
{[0.607]}\end{array}$ & - \\
\hline PE on GDP & $\begin{array}{l}5.031^{*} \\
{[2.745]}\end{array}$ & $\begin{array}{c}10.793 * * * \\
{[3.127]}\end{array}$ & $\begin{array}{c}-0.395 * * * \\
{[0.089]}\end{array}$ \\
\hline S\&P500 return & $\begin{array}{c}-0.002 \\
{[0.013]}\end{array}$ & $\begin{array}{c}-0.082 * * \\
{[0.037]}\end{array}$ & $\begin{array}{l}-0.006^{*} \\
{[0.003]}\end{array}$ \\
\hline PE firm fixed effects & No & No & Yes \\
\hline Industry dummies & Yes & Yes & No \\
\hline Calendar year dummies & Yes & Yes & Yes \\
\hline Number of Observations & 726 & 726 & 726 \\
\hline Number of PE firms & 131 & 131 & 131 \\
\hline R-squared & 0.468 & 0.610 & 0.881 \\
\hline F-stat & $7.00 * * *$ & $31.06^{* * *}$ & $73.81 * * *$ \\
\hline
\end{tabular}

Notes. Robust standard errors, clustered at the PE firm level, are reported in brackets. $* * * \mathrm{p}<0.01, * * \mathrm{p}<0.05, * \mathrm{p}<0.10$. 
TABLE 4 Linear Probability Model with PE Firm Fixed Effects Predicting the Probability of Raising a Second Fund

\begin{tabular}{|c|c|c|c|c|c|}
\hline & M1 & M2 & M3 & M4 & M5 \\
\hline \multicolumn{6}{|l|}{ Independent variables } \\
\hline Unrealized performance & - & $\begin{array}{c}0.022 * * * \\
{[0.008]}\end{array}$ & $\begin{array}{c}0.026 * * * \\
{[0.008]}\end{array}$ & $\begin{array}{c}0.025 * * * \\
{[0.008]}\end{array}$ & $\begin{array}{c}0.027 * * * \\
{[0.008]}\end{array}$ \\
\hline Realized performance & - & $\begin{array}{c}0.035^{* * *} \\
{[0.009]}\end{array}$ & $\begin{array}{c}0.035 * * * \\
{[0.010]}\end{array}$ & $\begin{array}{c}0.036^{* * *} \\
{[0.010]}\end{array}$ & $\begin{array}{c}0.036 * * * \\
{[0.009]}\end{array}$ \\
\hline \multicolumn{6}{|l|}{ Moderator } \\
\hline Media attention & - & $\begin{array}{c}0.027 * * \\
{[0.011]}\end{array}$ & $\begin{array}{l}0.027 * * \\
{[0.011]}\end{array}$ & $\begin{array}{c}0.026 * * \\
{[0.011]}\end{array}$ & $\begin{array}{l}0.026 * * \\
{[0.011]}\end{array}$ \\
\hline \multicolumn{6}{|l|}{ Interaction effects } \\
\hline $\begin{array}{l}\text { Unrealized performance } \\
\text { x Media attention }\end{array}$ & - & - & $\begin{array}{c}0.011 * * * \\
{[0.004]}\end{array}$ & - & $\begin{array}{c}0.009^{*} \\
{[0.005]}\end{array}$ \\
\hline $\begin{array}{c}\text { Realized performance } \\
\text { x Media attention }\end{array}$ & - & - & - & $\begin{array}{c}-0.005 \\
{[0.004]}\end{array}$ & $\begin{array}{c}-0.003 \\
{[0.005]}\end{array}$ \\
\hline \multicolumn{6}{|l|}{ Controls } \\
\hline Fund age & $\begin{array}{c}0.077 * * * \\
{[0.012]}\end{array}$ & $\begin{array}{c}0.051 * * * \\
{[0.012]}\end{array}$ & $\begin{array}{c}0.049 * * * \\
{[0.013]}\end{array}$ & $\begin{array}{c}0.050 * * * \\
{[0.012]}\end{array}$ & $\begin{array}{c}0.049 * * * \\
{[0.012]}\end{array}$ \\
\hline Fund age squared & $\begin{array}{c}-0.004 * * * \\
{[0.001]}\end{array}$ & $\begin{array}{c}-0.003 * * * \\
{[0.001]}\end{array}$ & $\begin{array}{c}-0.003 * * * \\
{[0.001]}\end{array}$ & $\begin{array}{c}-0.003 * * * \\
{[0.001]}\end{array}$ & $\begin{array}{c}-0.003 * * * \\
{[0.001]}\end{array}$ \\
\hline Called capital & $\begin{array}{c}0.027 \\
{[0.020]}\end{array}$ & $\begin{array}{c}0.008 \\
{[0.019]}\end{array}$ & $\begin{array}{c}0.010 \\
{[0.019]}\end{array}$ & $\begin{array}{c}0.005 \\
{[0.019]}\end{array}$ & $\begin{array}{c}0.008 \\
{[0.019]}\end{array}$ \\
\hline S\&P500 return & $\begin{array}{c}-0.003 \\
{[0.003]}\end{array}$ & $\begin{array}{c}-0.002 \\
{[0.003]}\end{array}$ & $\begin{array}{c}-0.002 \\
{[0.003]}\end{array}$ & $\begin{array}{c}-0.002 \\
{[0.003]}\end{array}$ & $\begin{array}{c}-0.002 \\
{[0.003]}\end{array}$ \\
\hline PE on GDP & $\begin{array}{c}0.037 \\
{[0.075]}\end{array}$ & $\begin{array}{c}0.020 \\
{[0.072]}\end{array}$ & $\begin{array}{c}0.018 \\
{[0.071]}\end{array}$ & $\begin{array}{c}0.017 \\
{[0.071]}\end{array}$ & $\begin{array}{c}0.016 \\
{[0.070]}\end{array}$ \\
\hline PE firm fixed effects & Yes & Yes & Yes & Yes & Yes \\
\hline Calendar year dummies & Yes & Yes & Yes & Yes & Yes \\
\hline Number of observations & 1,057 & 1,057 & 1,057 & 1,057 & 1,057 \\
\hline Number of PE firms & 205 & 205 & 205 & 205 & 205 \\
\hline Adjusted R-squared & 0.265 & 0.287 & 0.289 & 0.288 & 0.289 \\
\hline F-Stat & $5.89 * * *$ & $6.51 * * *$ & $6.40 * * *$ & $6.33 * * *$ & $6.16^{* * *}$ \\
\hline
\end{tabular}

Notes. Robust standard errors, clustered at the PE firm level, are reported in brackets.

$* * * \mathrm{p}<0.01, * * \mathrm{p}<0.05, * \mathrm{p}<0.10$. 
FIGURE 1 Interaction Term: Unrealized Performance and Media Attention

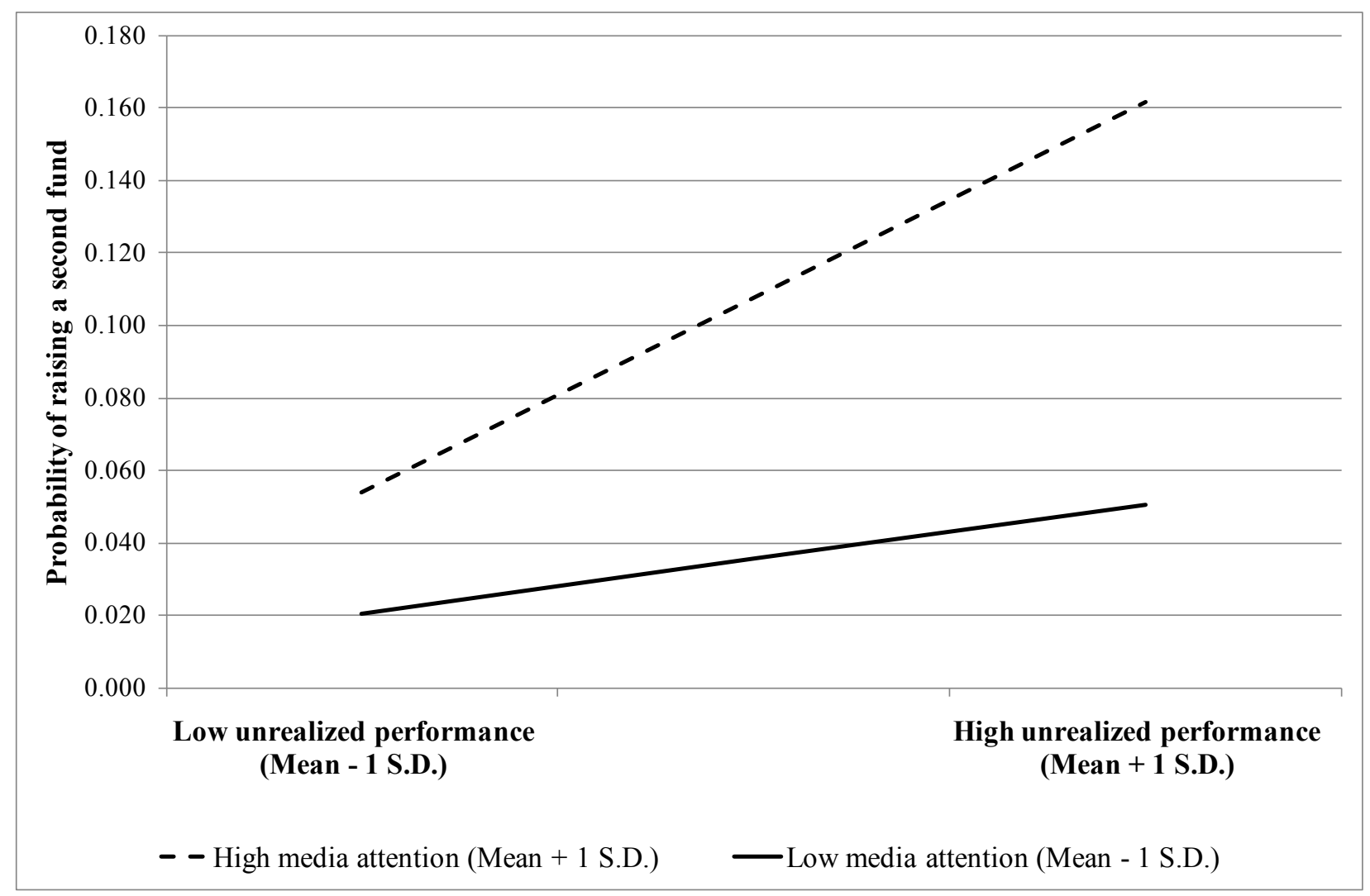


We supplemented our quantitative study with three qualitative, in-depth interviews. By doing so, we address an observation by Wiklund, Wright, and Zahra (2019) that "researchers increasingly rely on archival data in their research without ever interacting with entrepreneurs or other research subjects. ... Such interactions are extremely valuable. Insights into the setting and context enable researchers to understand if their findings are reasonable and make sense, and to interpret the deeper meaning and usefulness of specific statistical relationships" (p. 427) and that researchers could leverage insights from practice to "make the point, or even form the foundation for their theory" (p. 433).

We conducted two in-depth interviews with LPs and one with a GP (with prior experience as LP) during the winter of 2018/2019. Two interviewees were men, one was a woman. All interviewees have over ten years of experience in the PE industry, with multiple funds. One interviewee is currently a GP at a US-based PE firm, investing worldwide and having over \$1 billion in assets. The second interviewee is a managing director of the PE division of a financial institution, investing worldwide, but with a primary focus on Europe, currently managing around $\$ 1$ billion invested in approximately $60 \mathrm{PE}$ funds. The managing director has 15 years of experience as LP in PE funds. The third interviewee is an investment manager in a European fund-of-funds with currently around \$200 million invested in over $20 \mathrm{PE}$ funds. The interviewee has 10 years of experience as fund investor.

The interviews were semi-structured and lasted between 60 and 90 minutes. Two interviews were carried out face-to-face, whereas one was a telephone interview. We asked the LPs to provide insights into how they identify and evaluate first-time PE funds that are in fundraising mode, but also asked them to reflect upon their experiences with previous PE funds they had worked for, and to share their views on standard practices in the PE industry. We asked the GP to explain how he creates interest from LPs when fundraising, and how they then conduct their due diligence. To avoid interviewer bias, the face-to-face interviews were conducted by two of the authors. Further, the interviews were transcribed and analyzed by all of the authors.

In line with recent research that used quotes to bring life to theoretical considerations (e.g., Souitaris et al., 2019), we cannot claim to have followed a formal qualitative methodology. As it is particularly difficult to gain access to LPs, and especially to discuss topics which are at the core of their firm's strategy such as investing, we had to highly rely upon our networks in order to conduct these interviews, which took place under strict confidentiality. Nevertheless, the interviewees do reflect some heterogeneity in terms of role, gender, experience, location and geographical investment focus. 
Tom Vanacker (TomR.Vanacker@UGent.be) is an associate professor at Ghent University and a research professor at University of Exeter Business School. His research is focused on entrepreneurial finance. More specifically, he explores how entrepreneurs mobilize and deploy resources, especially financial, and how these resources impact venture development.

Daniel P. Forbes (forbe010@umn.edu) is an associate professor of strategic management \& entrepreneurship at the University of Minnesota, Carlson School of Management. He received his Ph.D. in management from New York University's Stern School of Business. His research is concerned with how people make decisions related to the creation, financing, and growth of new ventures.

Mirjam Knockaert (Mirjam.Knockaert@UGent.be) is an associate professor of entrepreneurship at Ghent University and a visiting professor at the Technical University of Munich. She received her Ph.D. in business economics from Ghent University. Her research focuses on technology transfer and the human capital aspects of early stage entrepreneurship.

Sophie Manigart (sophie.manigart@vlerick.com) earned her Ph.D. in management from Ghent University, and is currently full professor and faculty dean of Vlerick Business School and Ghent University. Her research interests focus on the financing process of entrepreneurial ventures, and especially on how ventures interact with different types of investors. 